\begin{tabular}{|c|c|c|c|c|c|}
\hline MUNIBE Antropologia-Arkeologia & $n^{\circ} 70$ & $35-63$ & DONOSTIA & 2019 & ISSN 1132-2217 • elSSN 2172-4555 \\
\hline
\end{tabular}

\title{
Las varillas decoradas magdalenienses de Ezkuzta (País Vasco)
}

\section{The magdalenian decorated antler rods ("baguettes") of Ezkuzta (Basque Country)}

PALABRAS CLAVES: Sudoeste de Europa, Magdaleniense medio, varillas decoradas de asta, estilo pirenaico.

GAKO-HITZAK: Europako hegomendebaldea, Erdi Magdalen aldia, Adarrezko apaindutako hagaskak, Pirinear estiloa.

KEY WORDS: Southwestern Europe, Middle Magdalenian, decorated antler rods, cultural Pyrenean marker.

\section{Ignacio BARANDIARÁN ${ }^{(1)}$, Ana CAVA ${ }^{(1)}$, Alvaro ARRIZABALAGA ${ }^{(1)}$ y María-José IRIARTE-CHIAPUSSO ${ }^{(1,2)}$}

\section{RESUMEN}

En la excavación de la cueva de Ezkuzta (Azpeitia/Guipúzcoa; al nordeste del corredor cantábrico) se hallaron tres varillas aplanadas hechas en asta de cérvido (¿reno?). Dos de ellas están casi completas; se conservan fragmentos de una tercera. Sus fórmulas de decoración se corresponden con algunas de Isturitz y de otros sitios del Pirineo francés: son surcos espiraliformes o curvilíneos en dos de ellas e incisiones agrupadas en haces en la otra. Se consideran fósiles característicos del Magdaleniense medio pirenaico, entre aprox. 14500 y 13300 años BP.

\section{LABURPENA}

Ezkuztako haitzuloaren (Azpeitia/Gipuzkoa; kantauri aldeko korridorearen ipar-ekialdean) indusketetan oreindar (elur oreina?) adarrekin eginiko hiru hagaska topatu ditugu. Horietatik bi, ia osorik daude; hirugarren baten zatiak aurkitu izan ditugu ere bai. Beren apainketa patroiak Isturitzekoekin (eta beste pirinear haitzulokoekin ere bai) bat datoz: dira grabatutako espiralformako edo kurbadun hildoak bi kasuetan eta lerrokatutako inzisioak bestean. Halako apainduradun hagaskak Pirinear eremuko Erdi Magdalen aldiko fosil esanguratsutzat hartzen dira, egundik 14500 eta 13300 urte bitartekoak, gutxi gora behera.

\section{ABSTRACT}

In the excavation of Ezkuzta's cave (Azpeitia/Guipúzcoa; in northeastern Cantabrian corridor) three made smoothed rods (french. baguettes demi-rondes) of cervidae's antler (reindeer?) were found: two completes and fragments of the third one. His formulae of decoration correspond with some of Isturitz and of other sites of the french Pyrenees: they are curvilinear or spiraliform ruts in two of them and fine lines grouped in faeces in other one. These themes are considered to be cultural markers of the Pyrenean middle Magdalenien, between aprox. 14500 and 13300 years BP.

\section{INTRODUCCIÓN}

La cueva de Ezkuzta (Azpeitia, Gipuzkoa) es una cavidad fuertemente alterada debido a diversas afecciones recientes, como la proximidad de una cantera y el aprovechamiento como salto de agua de su surgencia. Las obras de canalización y embalsamiento realizadas en una de sus galerías han afectado a la circulación de agua por toda la cavidad (figura 1). Los importantes procesos postdeposicionales (naturales y antrópicos) sufridos por el registro sedimentario de la galería con registro arqueológico han limitado drásticamente su extensión (figura 2). Su potencial arqueológico fue descubierto en 1979 por miembros del Grupo Antxieta, quienes recogieron algunos materiales proce-

\footnotetext{
(1) Dpto. de Geografía, Prehistoria y Arqueología (UPV/EHU).

(2) Basque Foundation of Science (IKERBASQUE).
}

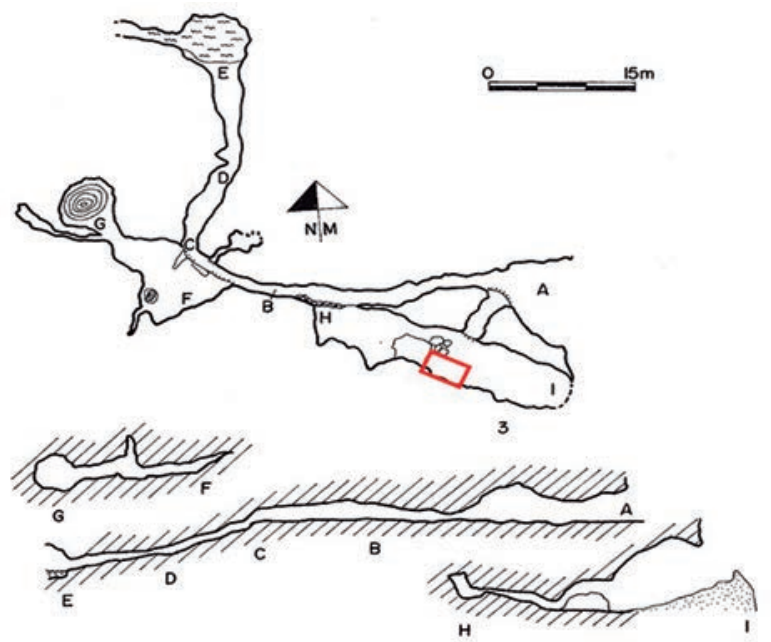

Fig. 1. Planta cueva de Ezkuzta y localización área de excavación (modificado de Altuna et al. 1995). / Ezkuzta cave plan, with the location of the excavation area (modified from Altuna et al. 1995). 


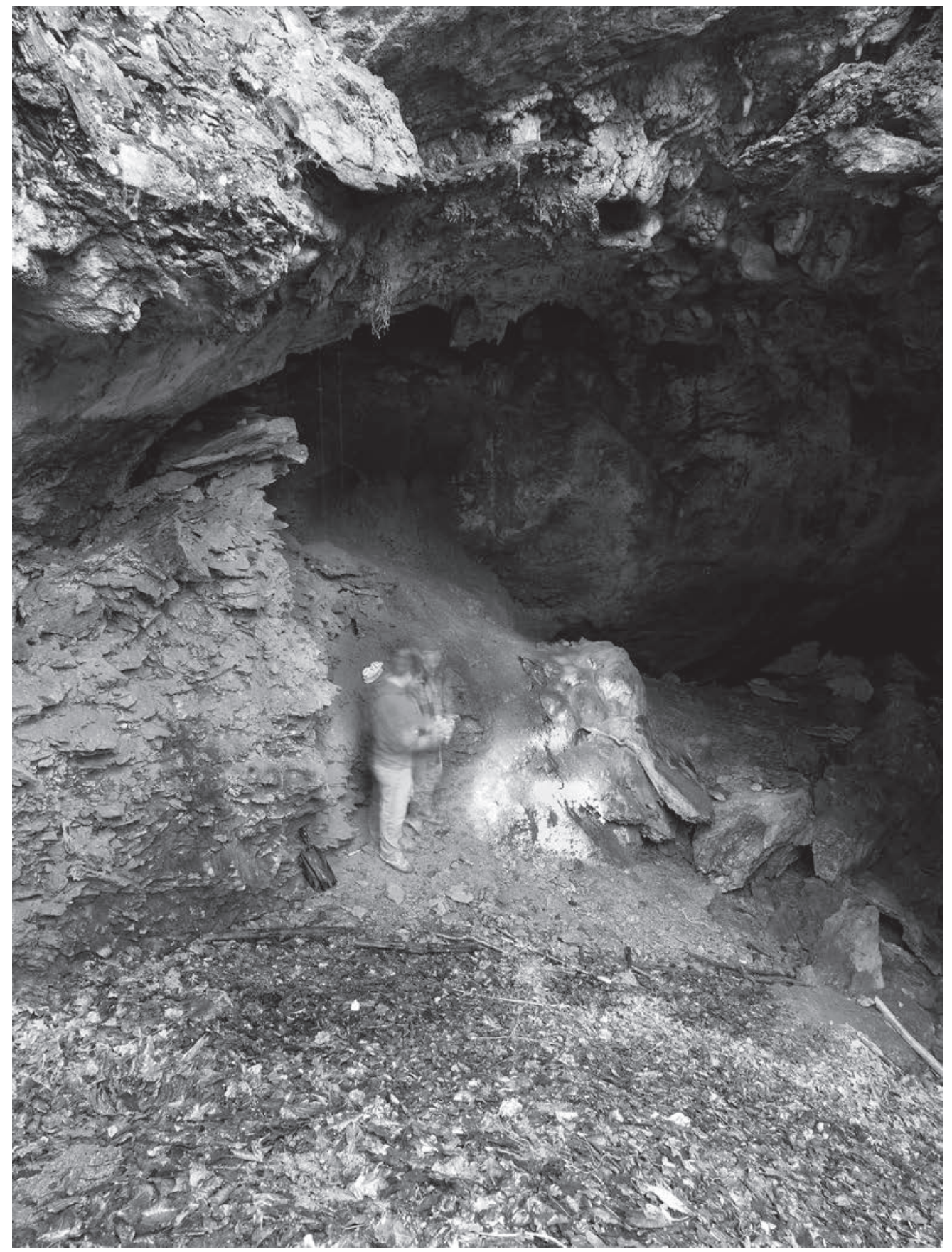

Fig. 2. Perfil sedimentario conservado en la década de los ochenta del siglo pasado (fotografía: Antxieta Arkeologia Taldea). / Sedimentary profile preserved in the eighties of the last century (photo: Antxieta Arkeologia Taldea).

dentes de una cata y superficiales (Altuna et al., 1995). Estos materiales líticos y faunísticos no permitieron definir ningún tipo de adscripción cultural.

Tras las fuertes lluvias caídas en el otoño de 2011 se produjo el colapso de una parte del ya menguado testigo. Ante esta situación, acordamos con la Diputación Foral de Gipuzkoa realizar con carácter de urgencia un estudio de la potencialidad arqueológica del sitio. De este modo, en 2012, se iniciaron los trabajos arqueológicos que continúan en la actualidad, bajo la dirección de $\mathrm{M}^{a}$ José Iriarte-Chiapusso.
Pese a la reducida extensión de la zona excavada, y a la alta densidad de clastos presentes en el registro estratigráfico, la relevancia de los materiales encontrados ha sido destacada. Además de diversos restos de industria lítica y faunísticos, hemos recuperado interesantes objetos de industria ósea, elementos de adorno y algunos hogares (Iriarte-Chiapusso, Antxieta Taldea, 2013, 2014, 2015, 2016, 2017, 2018). Todo ello, junto con las dataciones radiocarbónicas obtenidas, ratifica la ocupación de la cueva durante el Paleolítico superior. Entre estos materiales recuperados destacan las tres 
varillas decoradas que presentamos en este artículo. La restauración de las varillas se ha llevado a cabo en el Servicio de Restauración del Centro de Patrimonio Cultural Mueble de Gipuzkoa (GORDAILUA), por parte del conservador G. Studer.

\subsection{Varilla 3}

Siguiendo un desarrollo cronológico, la primera varilla se encontró en 2012, tras revisar el sedimento que había caído de una parte del cantil entre los cuadros L20/L22, tras un pequeño colapso. Evidentemente, esta varilla estaba fragmentada y en principio, descontextualizada (figura 3). Sin embargo, al revisar detalladamente el cantil intacto del que procedía, pudimos localizar un fragmento in situ lo que ha permitido ubicarla precisamente en el registro sedimentario (cuadro L20). Además, durante la segunda campaña de excavación (2013), localizamos un nuevo fragmento en el cuadro L22 (sector 5, capa 5).

Una vez consolidada y restaurada la pieza, se aprecia que la varilla está prácticamente completa (mide $181 \mathrm{~mm}$ de largo), a excepción de una reducida área de sus extremos distal y proximal (figura 4).

\subsection{Varilla 2}

En la campaña siguiente (2014), recuperamos la segunda varilla decorada en el mismo cuadro (L22, sector 4, capa 23). Por efecto de la presión de un gran clasto calizo apareció fragmentada, aunque conservando su morfología inicial. Esta varilla también está completa (salvo una pequeña parte de su extremo distal) y alcanza los $215 \mathrm{~mm}$ de longitud (figura 5).

\subsection{Varilla 1}

Durante el procesamiento de laboratorio de los materiales obtenidos en la campaña 2015, descubrimos los restos de una tercera varilla (L22, sector 5, capa 32). Se trata del ejemplar más fragmentado y erosionado y sus pequeños fragmentos (una docena, que miden entre 25 y $11 \mathrm{~mm}$ de longitud) corresponden a la zona medial de la misma (figuras $6 a, 6 b$ y $6 c$ ).

\section{ADSCRIPCIÓN TIPOLÓGICA}

Entre las manufacturas del Paleolítico superior sobre soportes orgánicos ${ }^{1}$ se llama varilla (fr. baguette, al. stäbchen) a la tira o listón de asta de cérvido (¿alguna se elaboró en marfil o en hueso?) de planta alargada y sección delgada aplanada con dos caras dominantes: más o menos curvada o convexa la superior o dorsal (correspondiente a la parte externa del asta) y plana o algo cóncava la inferior o ventral (la interna esponjosa). En el caso de las varillas semicilíndricas de la sala de St. Martin de Isturitz, su cara inferior es "tanto plana como fuertemente excavada en acanalado" (Saint-Périer, 1930: 56-57 y fig. 41.2). La mayoría tiene sección

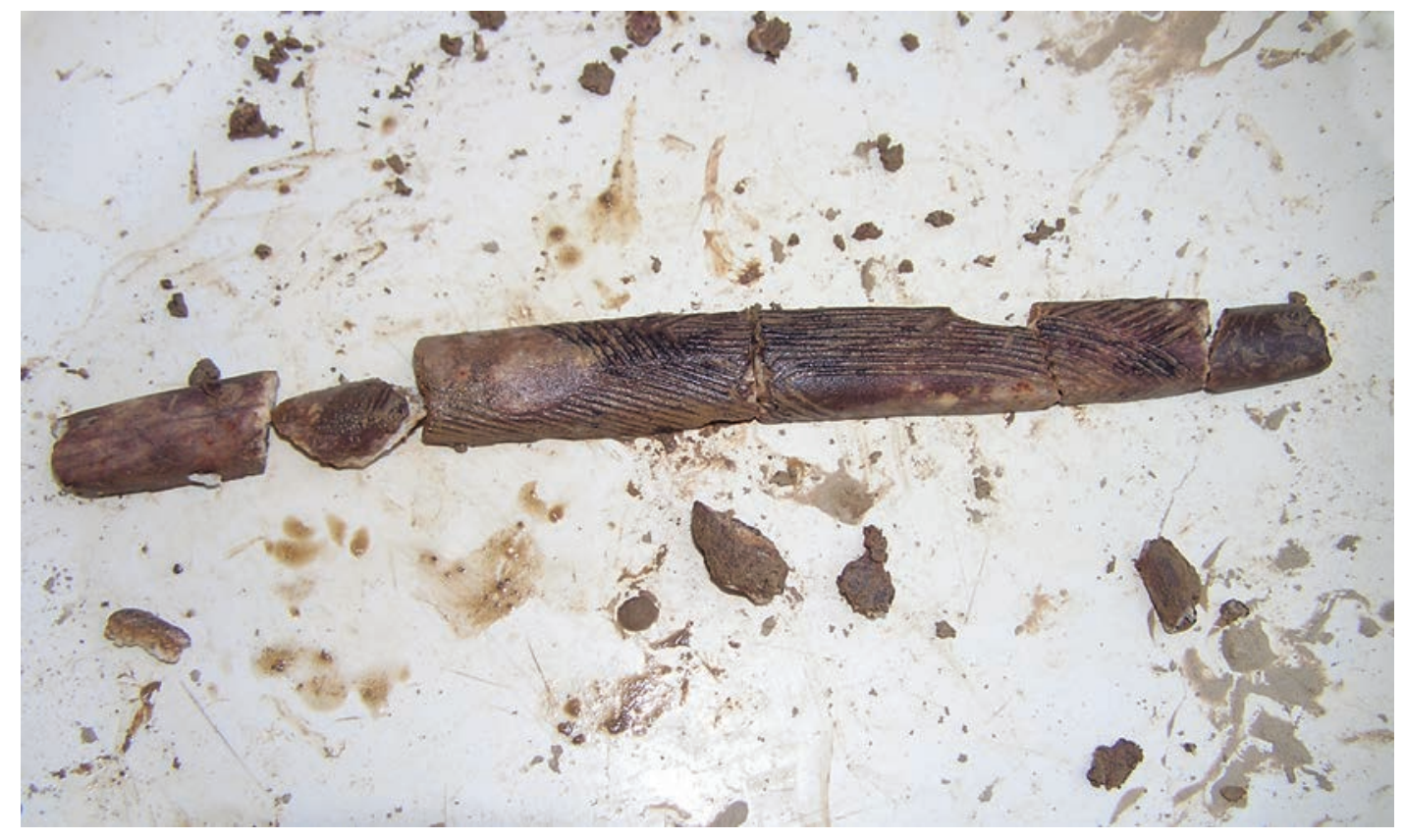

Fig. 3. Estado original de la varilla 3 en el momento de su descubrimiento (fotografía: Antxieta Arkeologia Taldea). / Original statement of antler rod 3 at the time of its discovery (photo: Antxieta Arkeologia Taldea).

\footnotetext{
${ }^{1}$ En general: Passemard, 1916: 302-304; Breuil y Lantier, 1959: 178; Cheynier, 1965: 151; Mons, 1981; Bosinski, 1990: 180-181; etc. Específicamente Barandiarán, 1967: 305-309, Barandiarán, 2006: 49-51 y 69 y Feruglio, 1992: aquél estudió en directo una amplia representación de varillas del sudoeste de Europa y pretendió repasar exhaustivamente su bibliografía; ésta ha preferido examinar una 'muestra de referencia' (838 evidencias de los sitios pirenaicos de Enlène e Isturitz) contextualizándola con una limitada lista de textos ajenos.
} 


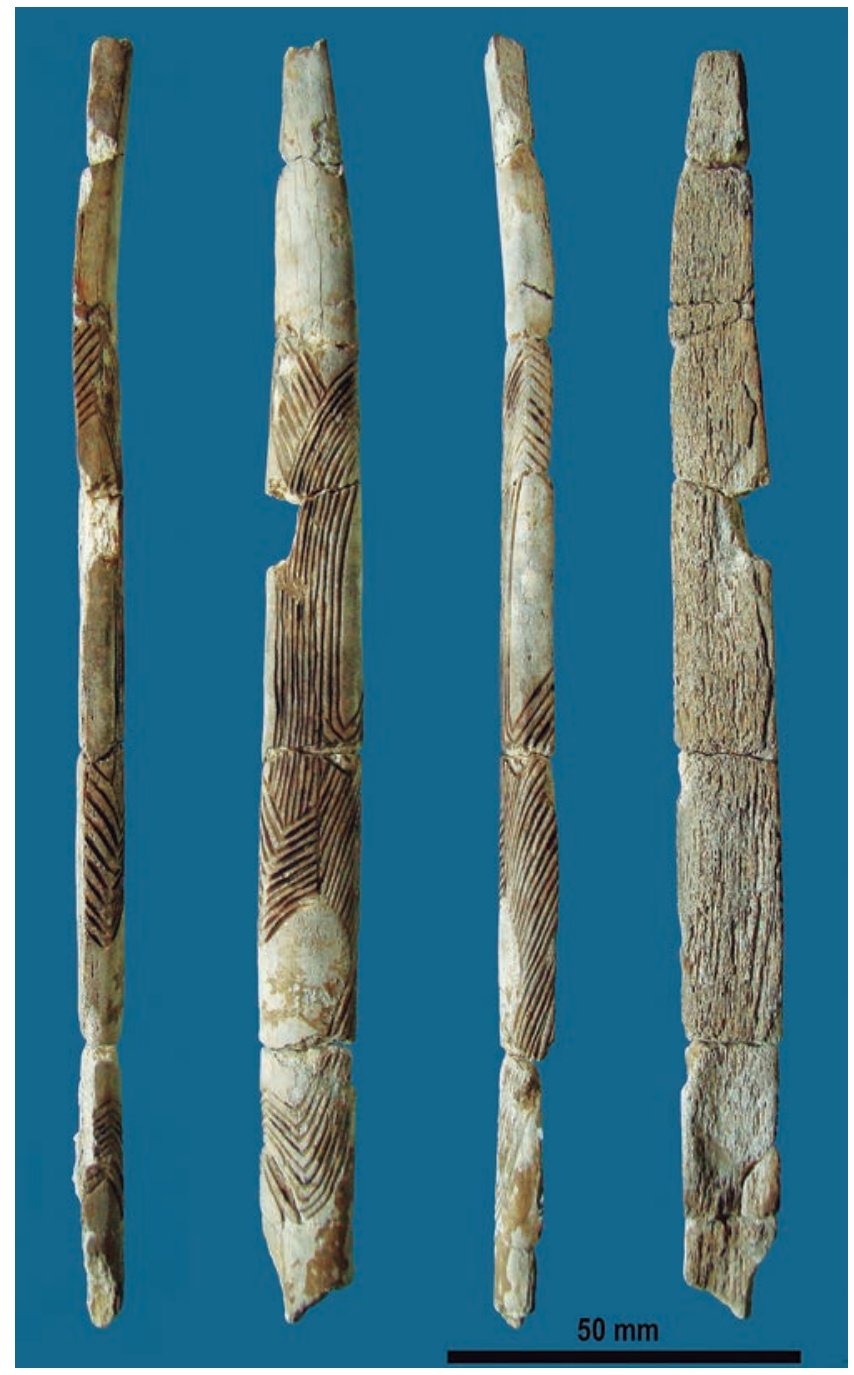

Fig. 4. Varilla 3: vistas lateral izquierda, dorsal, lateral derecha y ventral (mide 181 de longitud y 6.6 de espesor máximo). / Rod 3: left side, dorsal, right side and ventral views (measures 181 length and 6.6 thickness maximum).
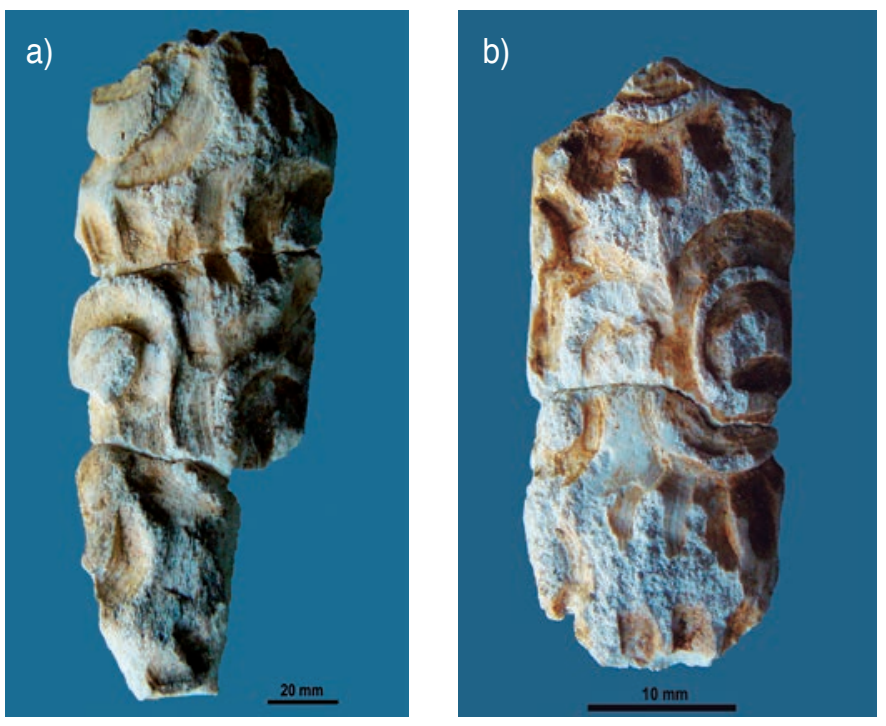

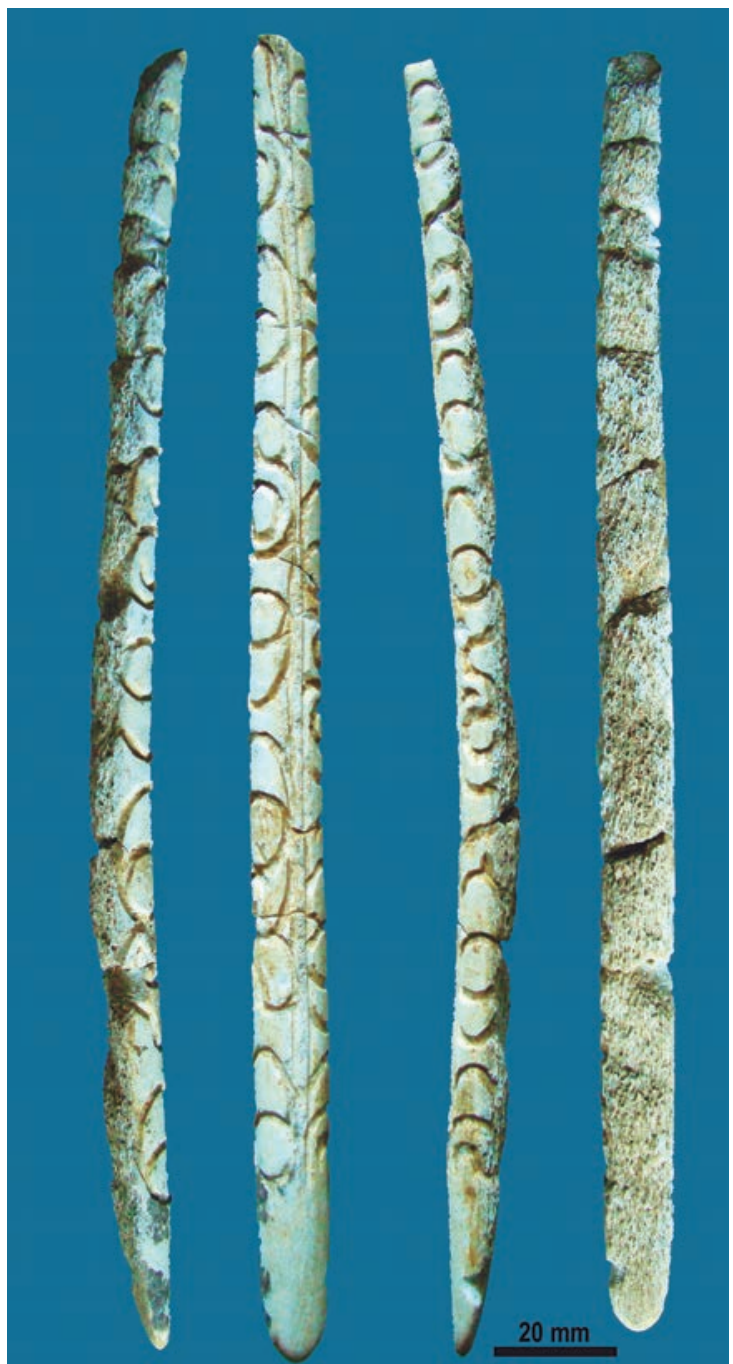

Fig. 5. Varilla 2: vistas lateral izquierda, dorsal, lateral derecha y ventral (mide $215 \mathrm{~mm}$ de longitud y 9,3 de espesor) / Rod 2: left side, dorsal, right side and ventral views (measures $215 \mathrm{~mm}$ in length and 9.3 in thickness).

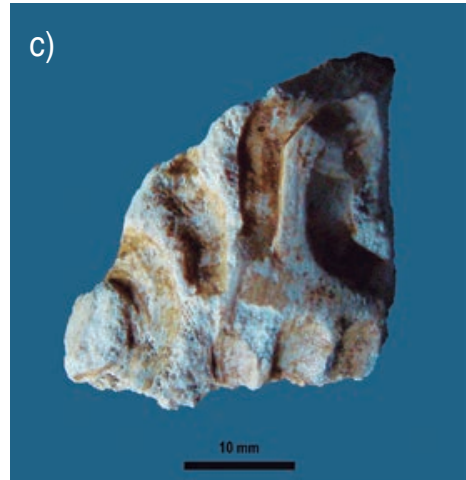

Fig. 6. Varilla 1: a) cara dorsal del fragmento mayor (mide $49 \mathrm{~mm}$. de largo y $18 \mathrm{~mm}$. de anchura); b) Varilla 1: cara dorsal del fragmento mediano (mide $41 \mathrm{~mm}$. de largo y $18 \mathrm{~mm}$. de anchura) y c) Varilla 1: cara dorsal del fragmento menor (mide $20,5 \mathrm{~mm}$. de largo y $20 \mathrm{~mm}$. de anchura). / Rod 1: a) dorsal side of the major fragment (measures $49 \mathrm{~mm}$ long and $18 \mathrm{~mm}$ wide); b) Rod 1: dorsal side of the medium fragment (measures $41 \mathrm{~mm}$. long and $18 \mathrm{~mm}$. wide) and c) Rod 1: dorsal side of the smaller fragment (measures $20.5 \mathrm{~mm}$. long and $20 \mathrm{~mm}$. wide). 
transversa aplastada (rectangular, suboval y planoconvexa o semicilíndrica); no muchas son de cuerpo masivo (subcircular). Bastantes llevan a todo lo largo de su cara inferior (o interna) trazos paralelos oblicuos (las que se llaman marcas de enmangue en otros útiles sobre asta o hueso) y decoraciones sobre la superior (o externa).

El análisis de originales y una convincente experimentación con réplicas reconocen la secuencia de su proceso de elaboración:

1. desprendimiento de una varilla (o listón) de asta.

2. alisado por raspado y pulido de sus superficies externa (eliminando sus irregularidades en relieve y dejándola más o menos plana o decididamente curvada) e interna (rebajando el tejido esponjoso hasta conformar un soporte aplanado y más masivo).

3. (¿0 4?) acondicionado de sus extremos distal y proximal.

4. (¿o 3?) adición de elementos 'decorativos' (sobre su cara dorsal) o 'funcionales' (sobre la opuesta).

La base (extremo proximal) de varillas aplanadas de Ermittia e Isturitz normalmente está (Barandiarán, 1967: 307-308) redondeada o apuntada; de modo excepcional se las dotó de un solo bisel sobre la cara dorsal o de uno o dos biseles oblicuos (en sendos lados izquierdo y derecho). Son las modalidades que se llamaron de 'bisel lateral' y de 'doble bisel lateral' (Saint-Périer, 1936). Las varillas de Ezkuzta presentan dos variantes de base: redondeada y con bisel simple sobre la cara inferior en la 2 y apuntada en la 3. Las tres se elaboraron en asta de cérvido: sus dimensiones son más acordes con la mayor esbeltez de los candiles de las cuernas del reno que con la robustez de los del ciervo.

Las varillas son relativamente frecuentes en la ecúmene europea desde el Gravetiense hasta el Magdaleniense final. Las caras dorsales de algunas acogen grabados (pocas veces algún tratamiento en relieve) de un variado signario en bandas (temas simples en paralelo, series de puntos, tubérculos, aspas, líneas etc.) o más complicados; y hasta algunas figuras.

La Arqueología propone que varillas no decoradas y decoradas tendrían destinos diferentes: aquéllas serían de uso más habitual, como los apuntados en asta (azagayas) convencionales; las decoradas se reservarían para fines 'no-utilitarios' (de representación, ornato, etc.).

En la campaña de excavaciones de 1913 en Isturitz, E. Passemard recuperó la excepcional evidencia de un empleo propio de tantas de esas manufacturas de sección aplanada: dos varillas muy largas prácticamente completas, similares (en su formato muy alargado, su sección semicircular y su decoración) que se adosarían por su cara ventral de dos en dos y adherirían con algún pegamento: "varillas gemelas, hechas para completarse y formar una sola y misma varilla de sección circular" (Passemard, 1916: 302-306 y fig. 1).
La decoración de las tres varillas de Ezkuzta ocupa totalmente su superficie dorsal: tanto su mayor parte curvada como sus contiguos estrechos planos (o extensiones) menores laterales (que, en el caso de la varilla 3, achaflanan en parte su sección plano-convexa).

Se suele aceptar que quienes en el Paleolítico superior grababan sobre soportes óseos se servían de buriles. El empleo de variantes de este utensilio sería exclusivo o completado con otros efectivos líticos (raspadores, filos no retocados, perforadores etc.). La limpieza de los surcos anchos y profundos de las varillas 1 y 2 de Ezkuzta y los trazos más finos de la 3 no pudieron producirse sólo con los tajos de cualquiera de los buriles habituales y es posible que su/s autor/es recurriera/n también a los filos no retocados y mucho más cortantes de pequeñas lascas o láminas de sílex.

\section{ANÁLISIS DE LAS VARILLAS DE EZKUZTA 3.1. Metodología}

El estudio de la morfología de soportes y técnicas y del proceso de ejecución de los grabados se asienta en su visión directa a su tamaño y ampliada (normal 2x y con estereomicroscopio 30x ENOSA y Nikon SMZ1500).

Para los dibujos hemos seguido el protocolo habitual de calco directo del original mediante rotulador de tinta permanente (Staedtler calibres 0,05, 0,1 y 0,2) sobre celofán muy fino; se amplía, corrige y retoca sobre ampliaciones y se asienta en tinta china; para superar dificultades de lectura (por mala conservación) de la varilla 1, se recurrió a calcos de fotografías a 2x. Los dibujos a línea han sido realizados por I. Barandiarán; A. Cava se hizo cargo del registro fotográfico de las varillas, tomado con una cámara Sony Ciber-Shot DSC-HP (a 1x, 5x y 10x). Agradecemos la aportación de Alejandro Prieto por las imágenes ampliadas de las figuras 30 a-e.

Para comparar este set de manufacturas (o sea, analizar la forma de su soporte y de su argumento gráfico y asentar comparaciones) se dispuso de un cuadro de contingencia (conservación, morfología, dimensiones, materia prima, tipología gráfica, etc.) elaborado a partir de la descripción y representaciones de los catálogos de E. Piette (1907), L. Coutil (1916), E. Passemard (1920, 1922), R. de Saint-Périer (1920, 1929, 1930, 1936), M. Chollot (1964), I. Barandiarán (1972), R. Arambourou (Arambourou et al., 1978), G. Bosinski (1978), C. Fritz y A. Roussot (1999), G. Sauvet (Sauvet et al., 2008), etc. Este cuadro contrasta los datos de la mayoría (todas las aceptablemente conservadas) de las varillas del Magdaleniense con grabados anchos curvilíneos entre los que se destacan molduras en relieve (32 varillas de Isturitz, 8 de Espélugues/Lourdes, 6 de Harpons/Lespugue, 5 de Espalungue/Arudy, 3 de Arancou/Bourrouilla, 1 de Sorde/Duruthy, 1 de Mas d'Azil, 1 de Hornos de la Peña y 1 de Poggenwisch), como son las varillas 1 y 2 de Ezkuzta y de las deco- 
radas con haces de líneas curvadas combinadas con áreas reservadas (7 de Isturitz, 3 de Espélugues/Lourdes y 1 de Hornos de la Peña), como la varilla 3.

Se presume que las superficies curvadas de las tres varillas acogen desarrollos de algún argumento (el total de las gráficas acogidas en cada soporte) con sus temas (dos sobre sendos campos, izquierdo y derecho de la varilla 2 y uno sobre los campos únicos de las 1 y 3) integrados por distintas unidades gráficas.

\subsection{Varilla 1}

\subsubsection{Descripción}

En la restauración de esta varilla, G. Studer ha conseguido agrupar los once restos (a excepción de tres trocitos) en tres fragmentos cuyos planos están desgastados/erosionados de antiguo:

- Fragmento mayor (donde encajan cinco trozos) mide 49,2 mm de longitud, 18,9 x 7,0 (en uno de sus extremos) y 18,3 x 6,6 mm (en el otro) de anchura $x$ espesor (figuras $6 a$ y 7 ). En su parte iz-

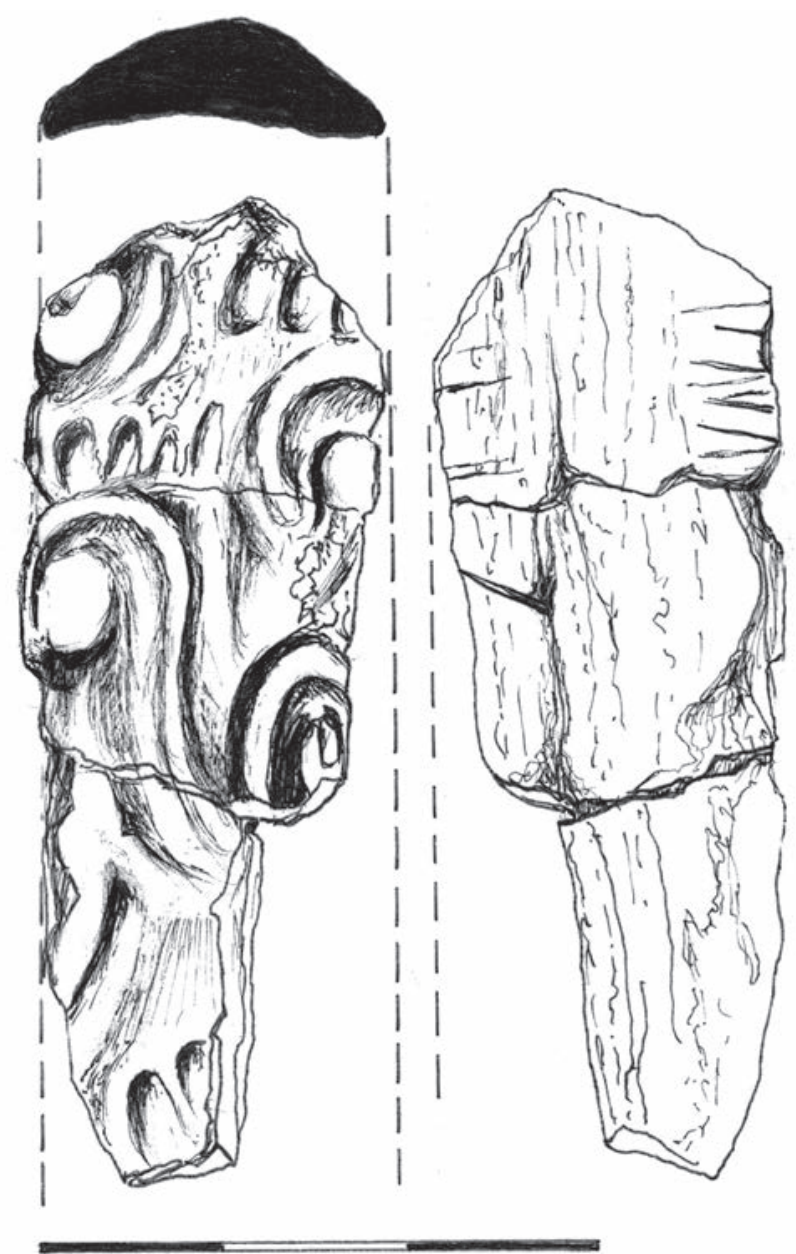

Fig. 7. Varilla 1: caras dorsal y ventral y sección transversal del fragmento mayor (escala de $3 \mathrm{~cm}$.). / Rod 1: dorsal and ventral sides and cross section of the major fragment ( $3 \mathrm{~cm}$ scale). quierda abajo presenta roturas/pérdidas de pátina reciente.

- Fragmento mediano (integrado por dos trozos) mide 41,1 mm de longitud y 18,1 x 6,5 (en un extremo) y $17,7 \times 6,5 \mathrm{~mm}$ (en el otro) de anchura $x$ espesor (figuras $6 \mathrm{~b}$ y $8 \mathrm{a}$ ).

- Fragmento menor - es un trozo de 20,4 x 19,9 x 7,0 $\mathrm{mm}$ de longitud $x$ anchura $x$ espesor (figura $6 \mathrm{c}$ y $8 b)$. En la parte distal presenta roturas/pérdidas de pátina reciente.

Todos ellos forman parte del tercio (sin llegar a la mitad) medial de una misma varilla de sección planoconvexa aplanada, extraída de un candil de asta de cérvido (acaso reno). En su cara superior convexa (la externa del asta) se grabaron/incidieron trazados curvilíneos de surco muy profundo y muy ancho. Su cara inferior fue alisada en plano para regularizar/eliminar parte del tejido esponjoso del interior del asta y acoger algunas incisiones paralelas grabadas finas que la cruzan de lado a lado en dirección casi perpendicular (ligeramente oblicua) (figura 9).

En la cara dorsal o externa del objeto se vieron afectadas por corrosión/erosión parte de las zonas del asta reservadas sin grabar (y que habían quedado como molduras/filetes en relieve entre los profundos surcos manufacturados) desapareciendo rugosidades del córtex del asta originaria y parte de la masa maciza interior inmediata; este deterioro afecta especialmente a la parte izquierda (según la orientación de las figuras $6 b$ y $8 a$ del fragmento mediano de la varilla. Se ha perdido, además, una banda central a lo largo de la cara inferior del objeto, estando bastante deshecha/inestable esa textura esponjosa.

\subsubsection{Propuesta de reconstrucción}

Faltando significados fragmentos intermedios de la varilla no es posible asentar el ensamblaje entre sí de los tres trozos conservados ni la orientación de cada uno de ellos hacia los extremos distal o proximal de la manufactura ni la continuidad de los temas grabados.

Atendiendo formatos de varillas similares se puede afirmar que los fragmentos de ésta de Ezkuzta son parte de un objeto alargado y estrecho. Nada se sabe sobre la conformación de sus base y punta.

Para tentar una reconstitución medianamente aceptable de la pieza y, en ella, la ubicación de los fragmentos recuperados sobre su presunta plantilla se valoran sus dimensiones y, en complemento, la forma previsible de las unidades gráficas de los dorsos y la orientación de las incisiones muy finas oblicuas subperpendiculares sobre las caras planas de los fragmentos mayor y mediano. Las dimensiones de las tres evidencias permiten ordenarlas en la serie decreciente del 'centro' hacia lo distal: fragmento menor - fragmento mayor - fragmento mediano. La coincidencia de las 


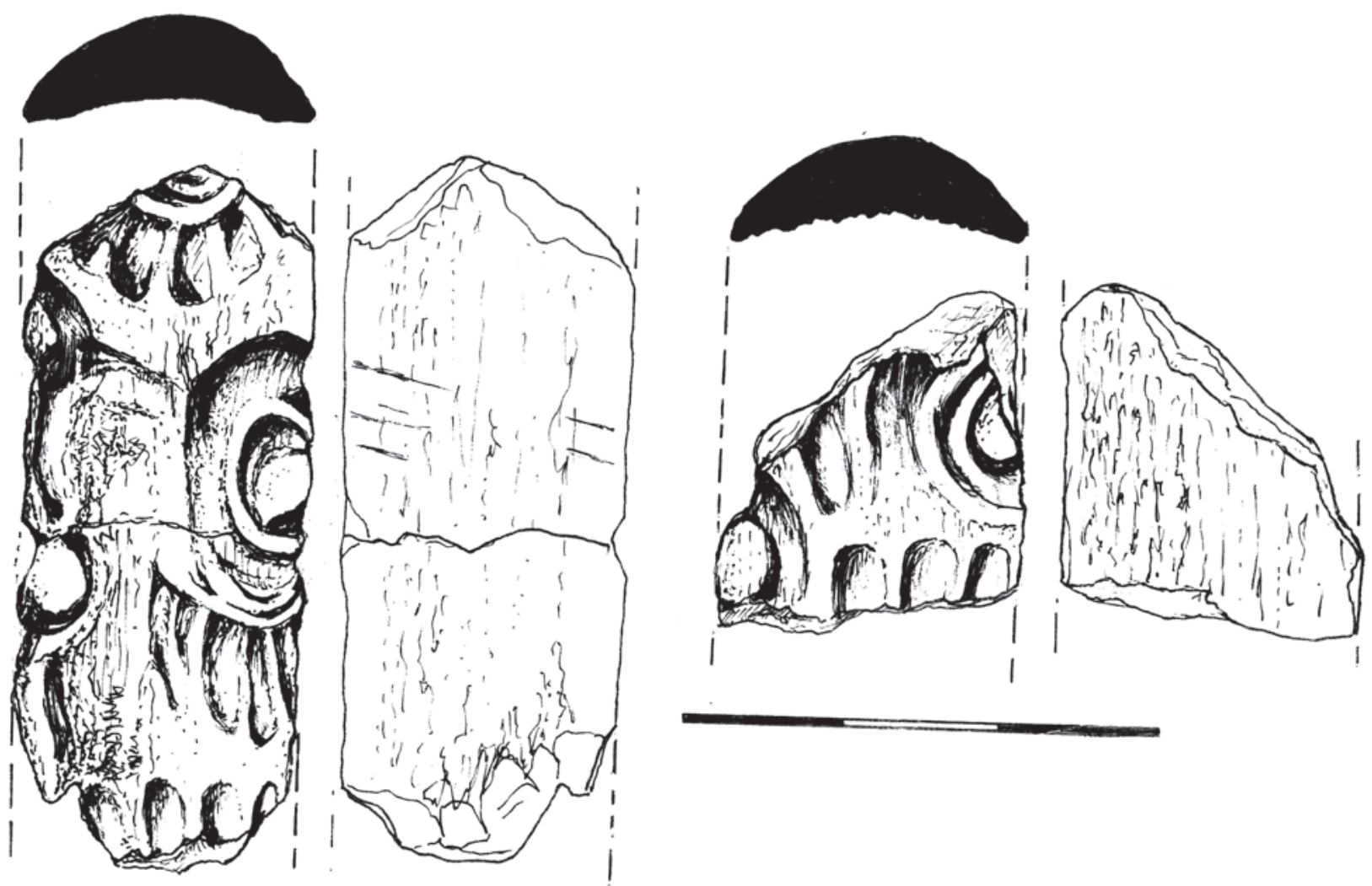

Fig. 8. Varilla 1: caras dorsal y ventral y secciones transversas de los fragmentos mediano y menor (escala de $3 \mathrm{~cm}$.). / Rod 1: dorsal and ventral sides and cross sections of the medium and smaller fragments ( $3 \mathrm{~cm}$ scale).

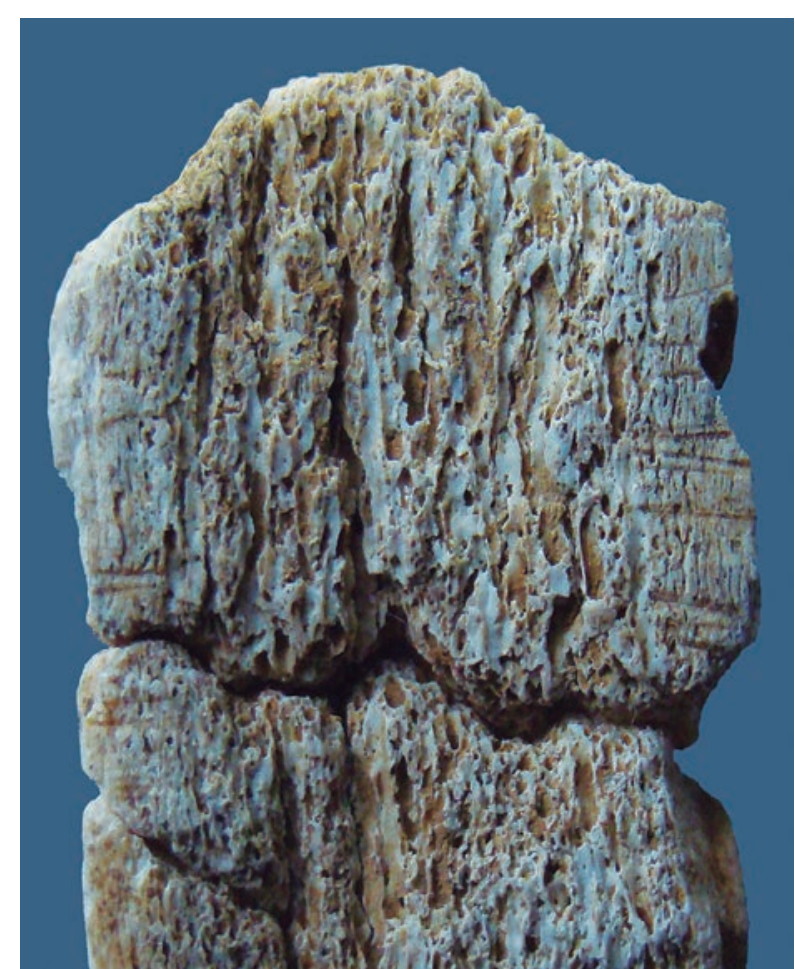

Fig. 9. Varilla 1: detalle de los trazos subhorizontales paralelos rayados sobre la cara ventral del fragmento mayor. / Rod 1: detail of the parallel subhorizontal traces on the ventral side of the greater fragment. líneas subperpendiculares de las caras ventrales de los dos fragmentos de mayor tamaño y la tentada secuencia del argumento gráfico que retienen los tres ayuda a orientarlos con relativa seguridad. No conocido el tamaño de los trozos no conservados, se puede tentar, con todas las reservas, una aproximación al tamaño de la varilla completa. En la figura 10 se presentan algunas posibilidades (en negro los fragmentos); la figura 11 la que parece más probable.

Atendiendo caracteres de las otras varillas más completas y con decoración similar a ésta de Ezkuzta, lo que se conserva de ella representaría algo menos de la mitad de una que midiera más de 245 sin llegar a los $280 \mathrm{~mm}$. de longitud: o sea, que era bastante larga, muy estrecha (no más de $20 \mathrm{~mm}$. de anchura en su parte central) y bastante delgada (no más de 7,3), 'muy esbelta' y 'muy aplanada' (índice de aplanamiento -anchura/espesor- de 2,59 en lo que pudo ser la parte central de la pieza -fragmento mayor- y de 2,76 en zona desplazada hacia los extremos).

\subsubsection{Técnicas y unidades del argumento gráfico}

En vista directa y sobre fotos de aproximación y macro se aprecia el resultado de la actuación insistente del grabador repasando lo trazado antes hasta conseguir los surcos anchos y profundos que han eliminado 

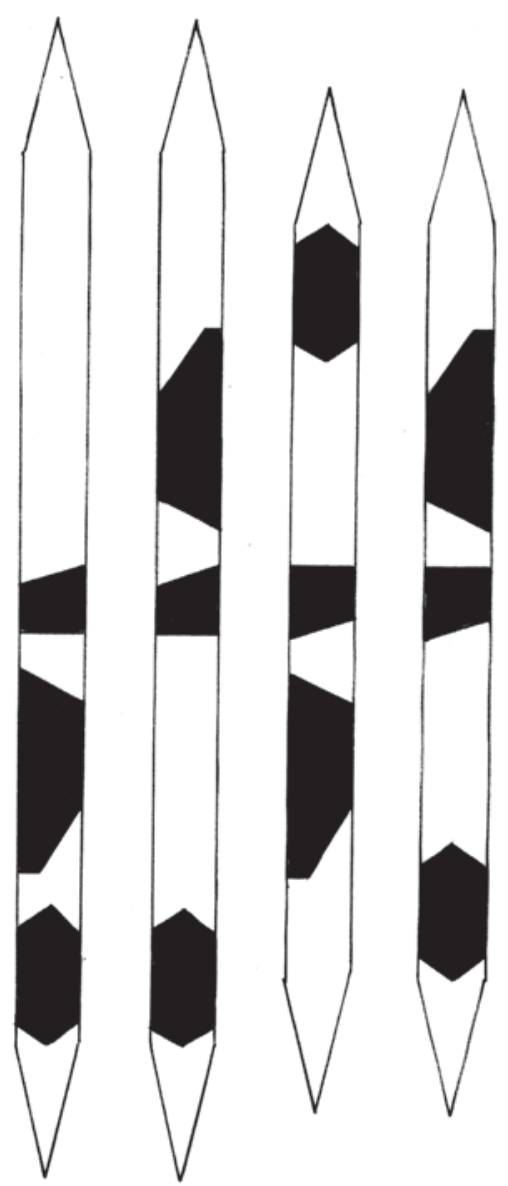

Fig. 10. Propuestas

de reconstitución de la pieza completa. / Reconstitution proposals of the complete piece.

un volumen apreciable del asta. La regularidad de esos trazados ahondados es notable: se asurcan con sección en $U$, de hasta $5 \mathrm{~mm}$. de anchura y de 2 a 3 de profundidad media (figuras 12 y 13).

Alcanzamos a individualizar once unidades gráficas sobre la cara dorsal de la varilla: cinco (dos mínimamente y tres medianamente conservadas) sobre el fragmento mayor, tres (dos partes mínimas y una aceptablemente conservada) sobre el mediano y tres (mínimas) sobre el menor. Tan corto muestrario (con una sola unidad gráfica que parece completa, tres que asentarían una discutible reposición y una media docena de partes mínimas de sendos temas) coincide en el mismo repertorio de desarrollos curvilíneos o espiraliformes individualizados por R. de Saint-Périer (1929: 54-60, figs. 8-12). Cada uno de los grafemas se compone de un 'circulo' y una serie (tres a cinco) de dientes adosados 'en sierra' (ibid., figs 10/1-13: son cavidades de sección en $U$ y de planta arqueada a modo de ova más o menos alargada). Cada compuesto círculo+dientes se prolonga/combina en/con el próximo mediante un trazado 'serpentiforme'.

Entre esos trazos fuertemente asurcados se reservan planos (donde se conserva el córtex del asta originaria) que destacan 'como en relieve'. Son extremadamente finos los filetes o molduras así preservados

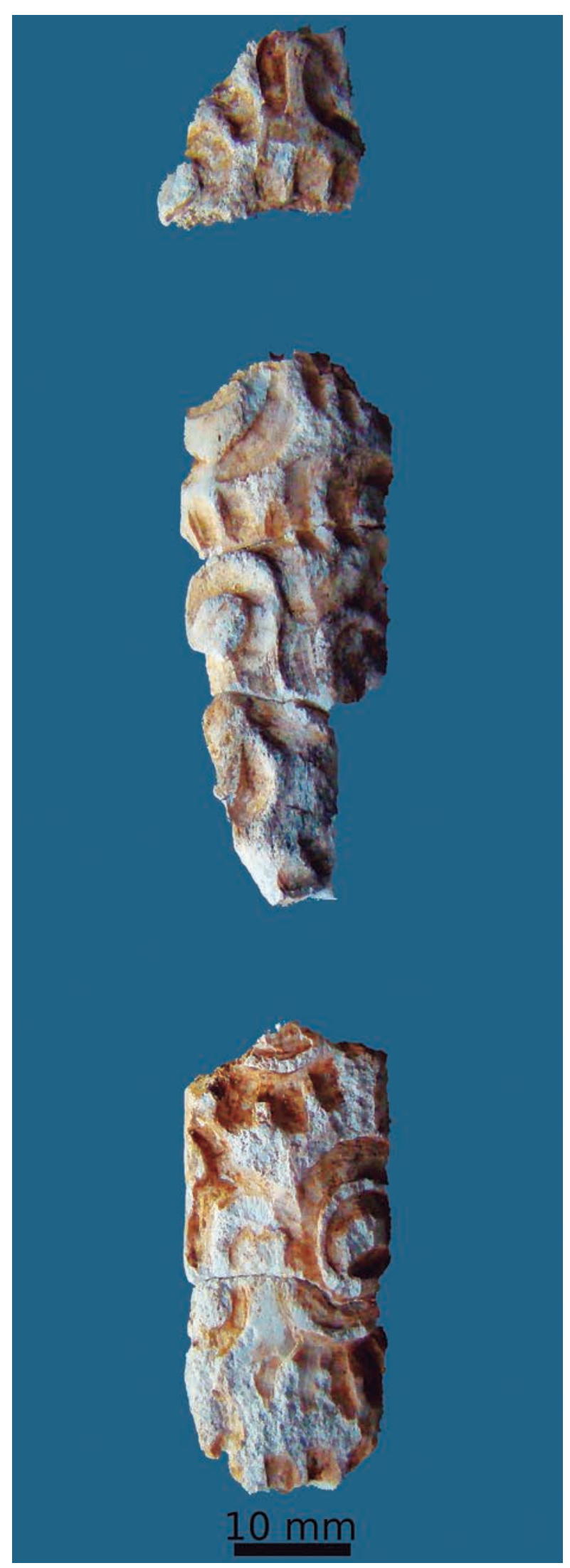

Fig. 11. Propuesta de ordenación de los fragmentos de la varilla 1. / Proposed sorting of rod 1 fragments. 


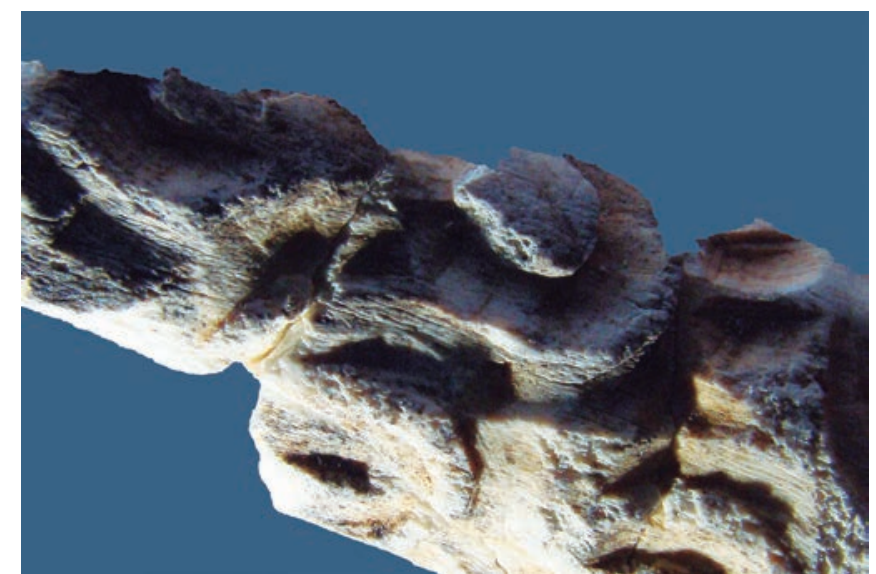

Fig. 12. Varilla 1: detalles de elaboración y repasado de los surcos en el fragmento mayor. / Rod 1: details of elaboration and redig of the grooves in the bigest fragment.

y que dan forma a los grafemas circulares del dorso de la varilla. La moldura del círculo menor, el situado en la parte centroderecha del fragmento mediano, tiene una anchura que oscila entre los 0,38 y los 1,32 mm; en lo conservado de los otros círculos, esas anchuras se mueven en el abanico de los 1,28 a 1,98 mm.

El argumento que componen las unidades gráficas asentadas en esta varilla de Ezkuzta cumplen con lo común a las asentadas sobre ejemplares magdalenienses pirenaicos, que, según observó R. de Saint-Périer, "se extienden por casi toda su superficie convexa... muy próximas entre sí sin ser simétricas..." (figura 14).

\subsection{Varilla 2}

\subsubsection{Descripción}

Esta varilla completa (a excepción de una parte de su extremo distal), tiene una longitud de $215 \mathrm{~mm}$ (completa mediría 250-260 mm). Su sección transversa es subcircular robusta (irregular por no haber sido eliminada completamente la parte interna del asta) y se afina desde el extremo proximal al distal tanto en anchura (desde 12,6 a 9,40 mm.) como en espesor (desde 9,3 a $7,5 \mathrm{~mm}$.) (figura 5 y 15).

En la base se dispuso un monobisel (sobre la cara inferior del soporte) liso y corto: sus $25 \mathrm{~mm}$. de largo suponen un décimo de la longitud de la pieza (figura $16 a$ y 16b). La punta (extremo distal) más fina pudiera haber estado tanto redondeada como ligeramente apuntada. Se elaboró sobre un candil de asta de cérvido (acaso reno).

\subsubsection{Análisis Técnico y formal de los grafismos}

Su argumento gráfico ocupa la cara dorsal y las dos contiguas laterales. Siguiendo la línea central del dorso del soporte se ha respetado una moldura longitudinal que dispone a uno y otro lado sendos campos

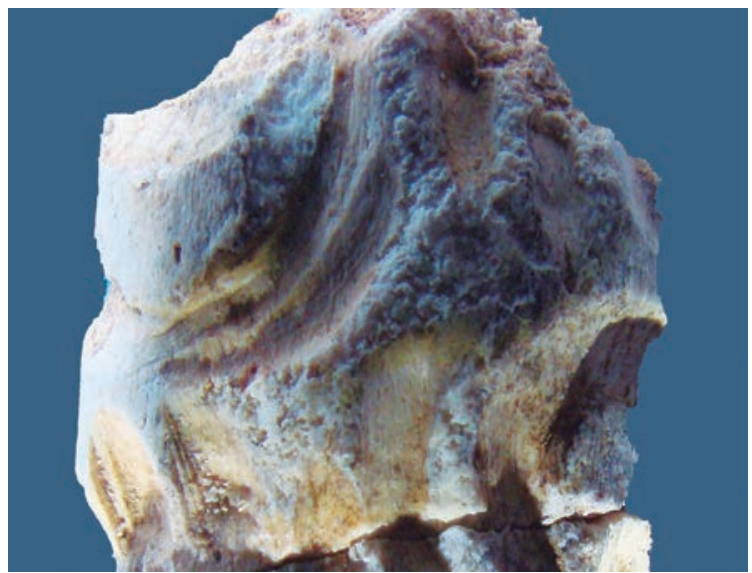

Fig. 13. Varilla 1: detalles de elaboración y repasado de los surcos en el fragmento menor. / Rod 1: details of elaboration and redig of the grooves in the smallest fragment.
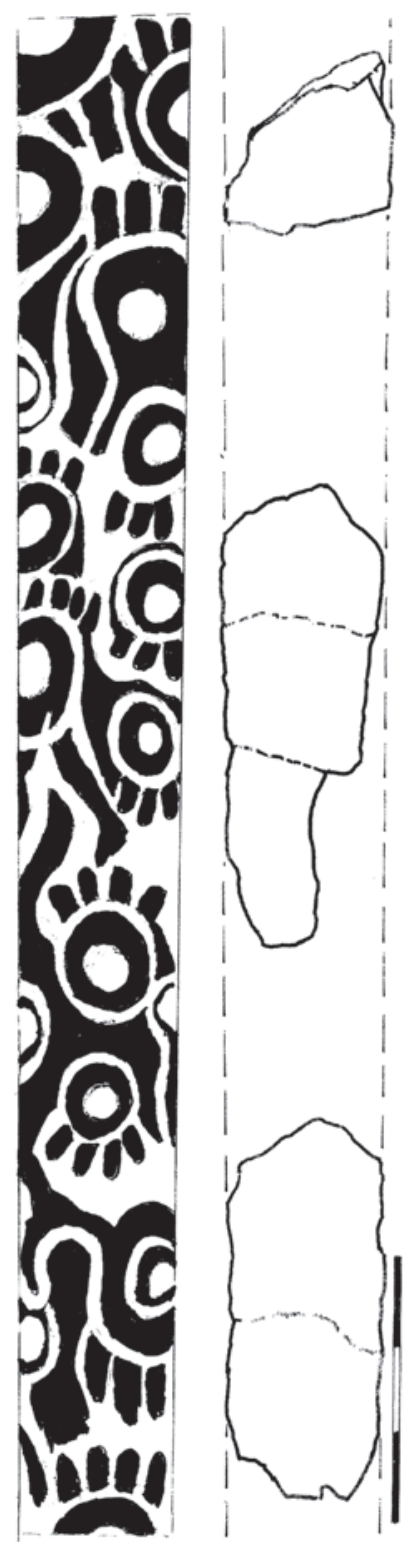

Fig. 14. Varilla 1: Propuesta de reconstitución del argumento gráfico. / Rod 1: Proposal for reconstitution of the graphic argument. 


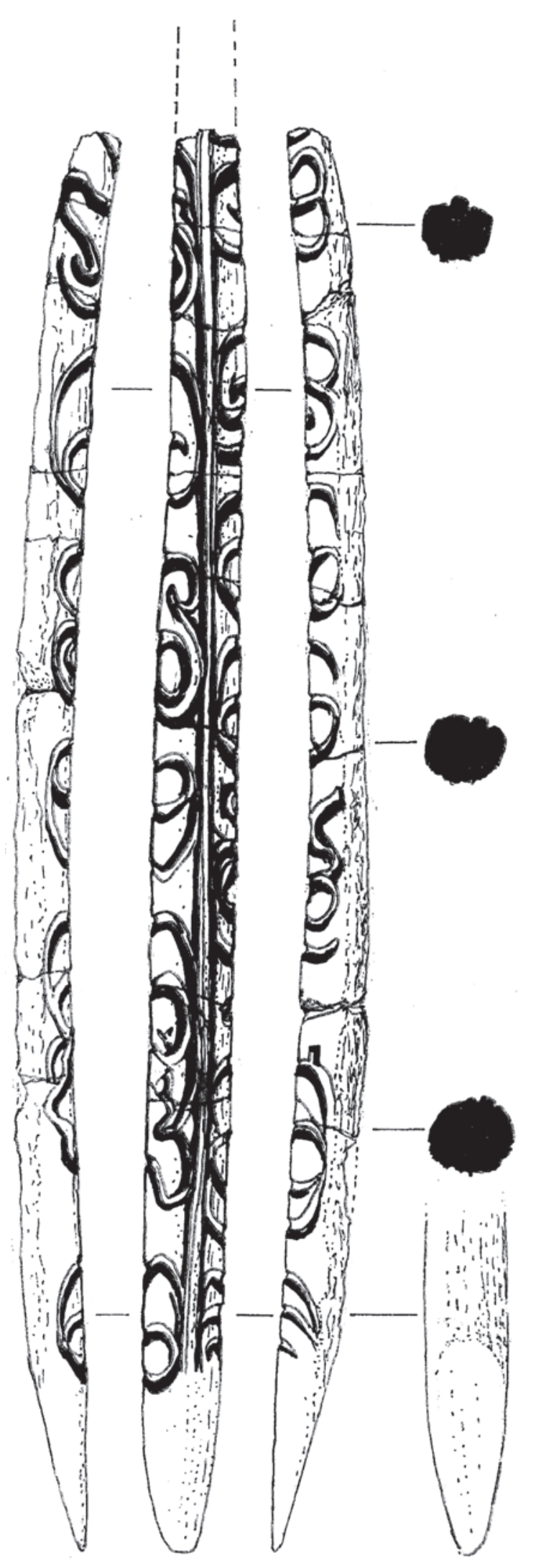

Fig. 15. Varilla 2: vistas lateral izquierda, dorsal y lateral derecha y secciones transversas. / Rod 2: left side, dorsal and right side views and cross sections.
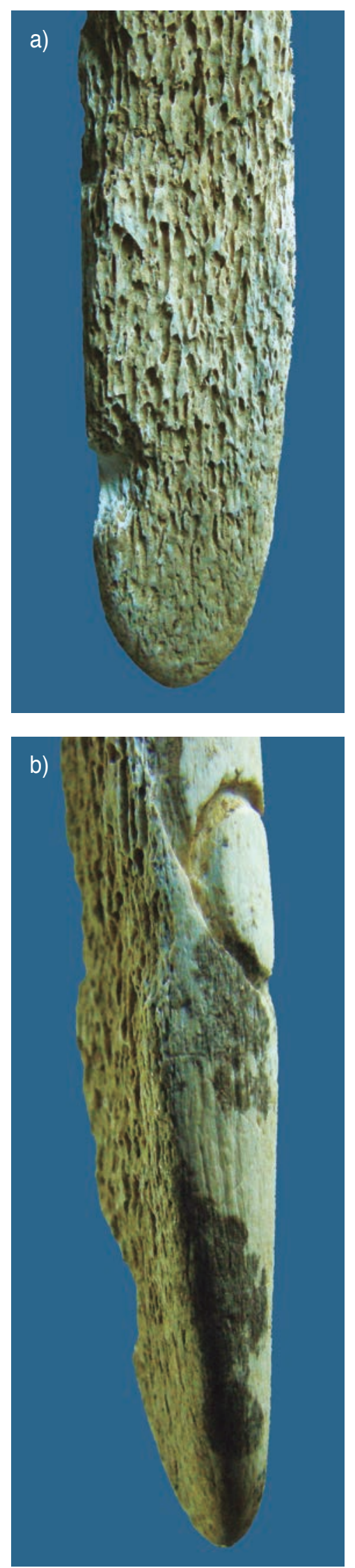

Fig. 16. Varilla 2: detalles del bisel: a) cara ventral; b) vista lateral. / Rod 2: bevel details: a) ventral face; b) side view. 
alargados que acogen grabados curvilíneos. Son muy marcados en profundidad y anchura los surcos de aquella moldura y de estos curvilíneos (figura 17).

El dorso de la moldura central está a ras de la superficie original del asta, por lo que conserva la estructura rugosa de su córtex. La moldura está definida por surcos que profundizan entre 1 y $1,5 \mathrm{~mm}$. del asta y tienen una anchura de 1,6 a 1,8 mm. (reducida a apenas 1,1 donde el surco fue invadido y parcialmente amortizado por las gráficas curvilíneas trazadas posteriormente) (figuras 18a y 18b).

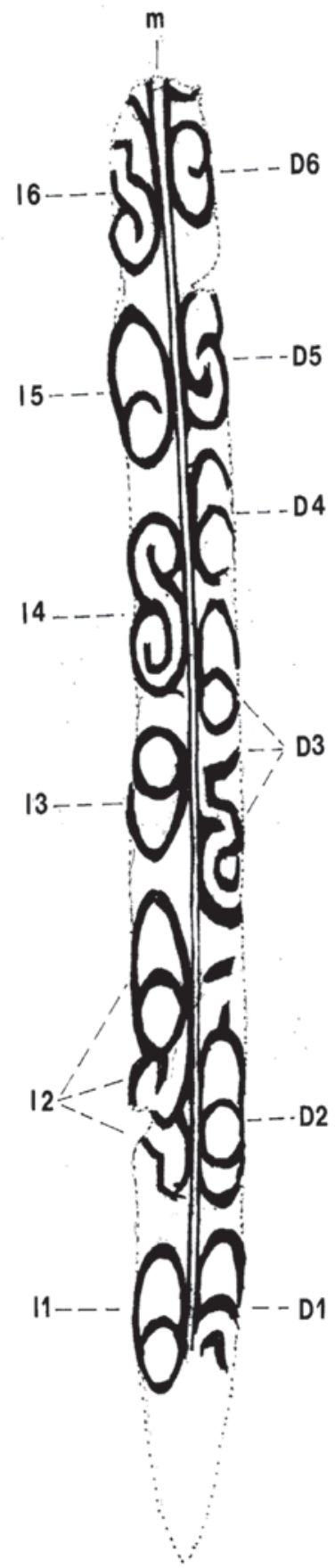

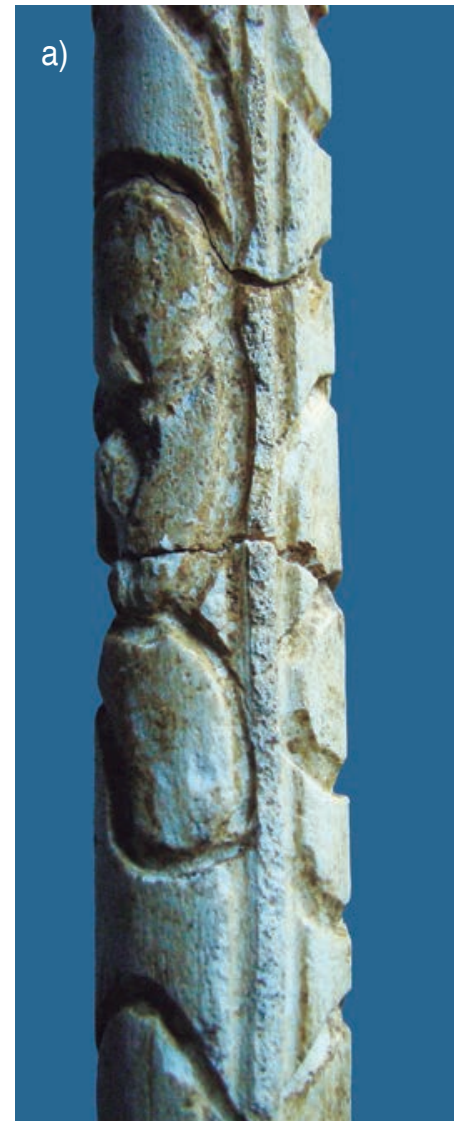

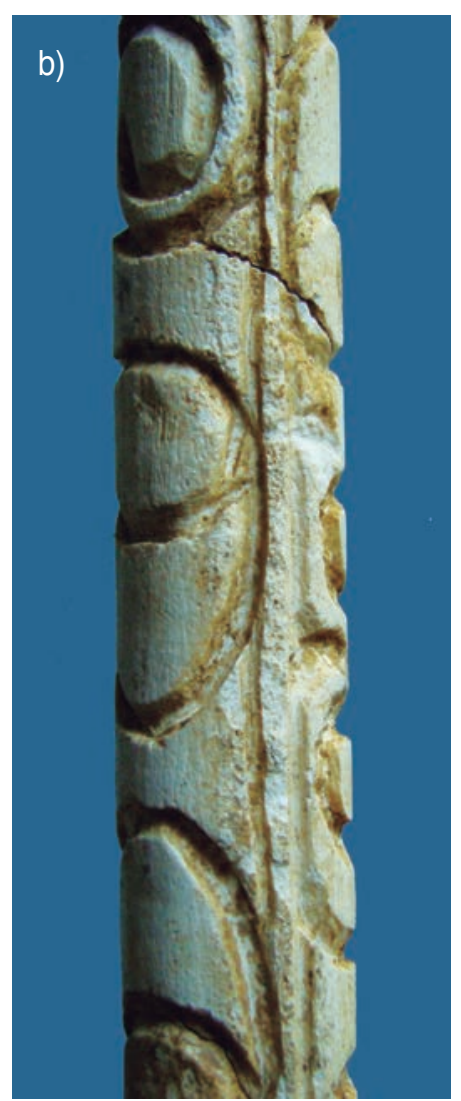

Fig. 18. Varilla 2: a) y b) detalles de la moldura en la mitad inferior de la pieza (zonas de las u.g. 12 y 13). / Rod 2: a) and $\mathbf{b})$ details of the molding in the lower half of the piece (areas of g.u. I2 and I3). 
El campo I(zquierdo) de la varilla está ocupado por seis unidades gráficas (u.g.), de abajo arriba (Figura. 17): un óvalo completo en cuyo tercio inferior se ubica un círculo (u.g. 11) (figura 19b); un complejo donde se adosan un serpentiforme irregular (abajo) y un ahovado con círculo interior (arriba) (dentro de este círculo hay tracitos cruzados de surco mucho más delgado) (u.g.
I2) (figura 21); una figura ovalada muy corta donde se incluye un círculo que ocupa su mitad superior (u.g. I3) (figura 19a); un serpentiforme (u.g. 14) (figuras 20a y 22a); un óvalo o ahovado (con un polo ligeramente apuntado) que incluye al revirarse sobre sí un círculo casi completo (u.g. 15) (figura 22b) y un serpentiforme irregular (u.g. 16).
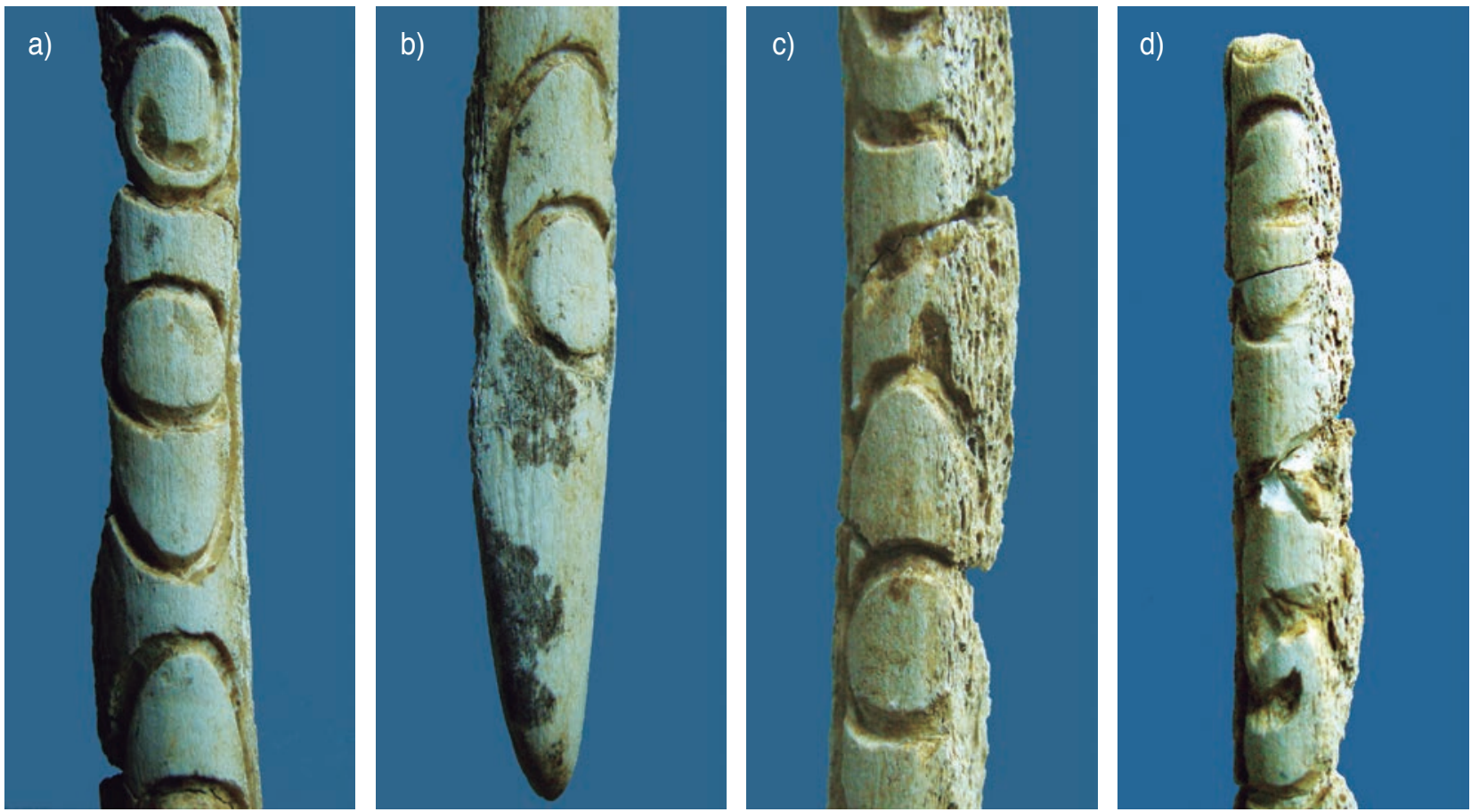

Fig. 19. Varilla 2: a, b, c y d detalle de las unidades gráficas I3, I1, D2 y D6 en forma de óvalo con circulo incluido. / Rod 2: a, b, $\mathbf{c}$ and $\mathbf{d}$ detail of the graphic units I3, I1, D2 and D6 in the form of an oval with circle included.

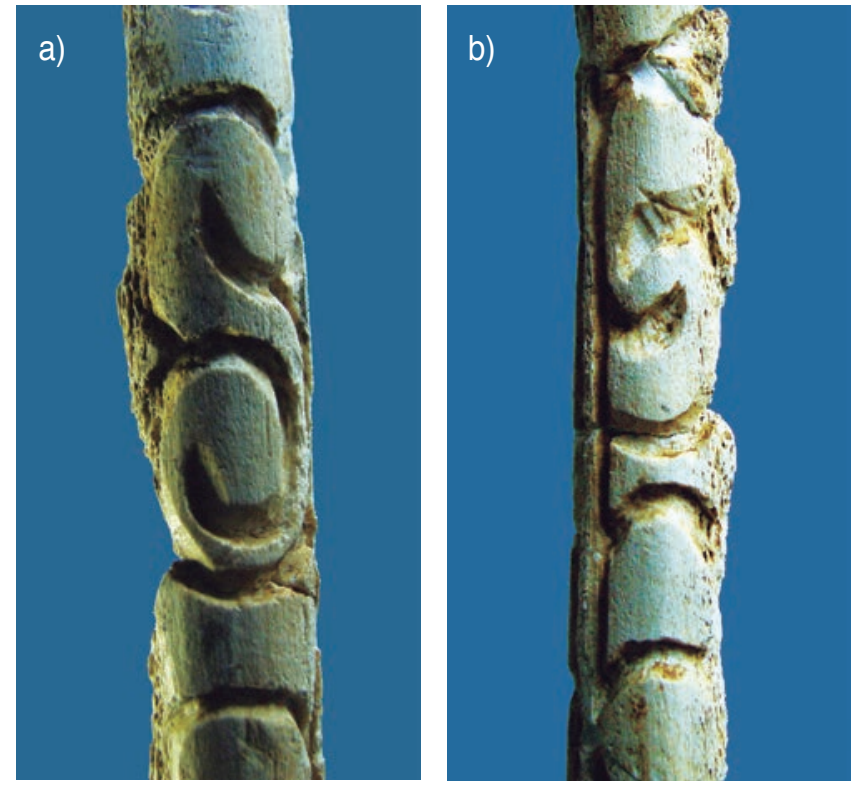

Fig. 20. Varilla 2: a) y b) detalle de las unidades gráficas 14 y D5 en forma de S. Rod 2: a) and b) detail of the graphic units 14 and D5 in the form of S.

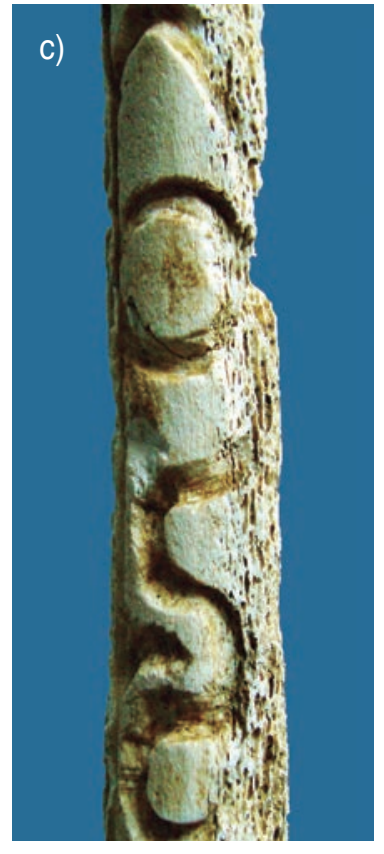

Fig. 21. Varilla 2: unidades gráficas 12 y D3, compuestas de óvalo con circulo incluido + S. / Rod 2: graphic units 12 and D3, composed of oval with circle included + S. 

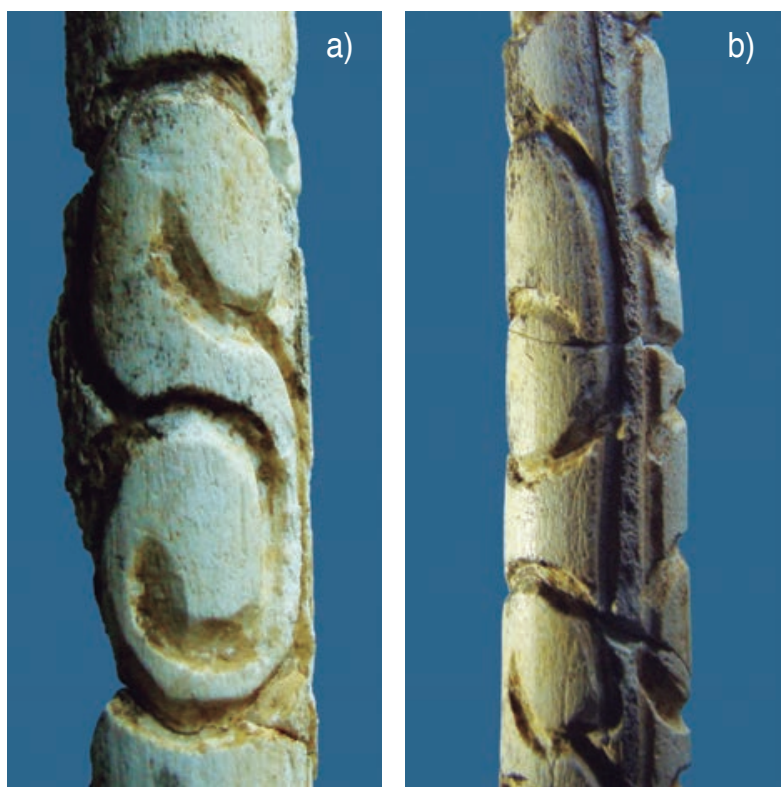

Fig. 22. Varilla 2: a) y b) detalles de técnicas de grabado/incidido en 14 y 15. / Rod 2: a) and b) details of engraving / incident techniques in 14 and I5.

Hay otras seis unidades gráficas (más el inicio de una séptima) a lo largo del campo D(erecho) de base a punta (Figura. 17): una figura formada por tres surcos oblongos paralelos (que si se hubieran dibujado cerrados sugerirían un óvalo incluyendo círculo) (u.g. D1); un óvalo completo con un tracito adosado al exterior de su polo superior y con círculo interior ocupando una posición algo desplazada (u.g. D2) (figura 19c); un conjunto de trazos con una forma serpentiforme irregular (abajo) y un ahovado con un círculo ocupando todo su tercio inferior (arriba) (u.g. D3) (figura 21); una figura ovalada con círculo dentro de su mitad inferior (u.g. D4); una forma en 'S' (u.g. D5) (figura 20b); un óvalo corto cerrado cuyo trazado superior derecho se vuelve sobre sí iniciando un círculo que ocupa casi la mitad de la figura (u.g. D6) (figura 19d) y el extremo final (por fractura de la varilla) de un trazo curvado (u.g. D7).

El diseño de todas esas unidades gráficas es cerrado (= vuelto sobre sí mismo) y alargado sea como ovalado o como serpentiforme (o en ' $\mathrm{S}$ '): diez son 'simples' (sólo ovalados las 11, 13, 15, D1, D2, D4 y D6; sólo serpentiformes las 14, 16 y D6) en tanto que 12 y D3 'combinan' ovalado con serpentiforme (figura 19a, 19b, 19c, 19d, 20a, 20b y 21). La morfología de todas se corresponde con los dos tipos generales de "en S" (o de dos espirales opuestas juntas) y "en óvalo" (o en almendra) bien individualizados en Saint-Périer (1929: respectivamente figs. 8.21-29 y 11.61-67).

Los grafismos ovalados (integrados por óvalo y círculo interior) son bastante similares en su construcción básica. Pero ofrecen tres variantes:

- forma oval más o menos regular (I1, D4 y D6) o ahovada (I2, I3, I5 y D3) y con formato alargado (I2, D2 y D3) o corto (I3, D4 y D6),
- que el círculo que ocupa su interior se sitúa en posición centrada (D2) o en uno de sus polos (todos los otros casos),

- que ese círculo no esté exactamente completo (sino formado por el trazo final del contorno del óvalo que gira sobre sí cerrándose y sugiriendo una figura de círculo: I.5 y D6) o sea forma completa (los demás).

Todas esas u.g. se disponen sueltas (sin contacto cada una con las inmediatas) y están en fila a uno y otro lado de la varilla con similares fórmulas de secuencia, alternándose $\mathrm{O}(\mathrm{Ovalado})$ con $\mathrm{S}($ Serpentiforme):

- en el campo izquierdo: O / S+O / O / S / O / S /...

- en el campo derecho: O? / O / S+O / O / S / O / ?

\subsubsection{Desarrollo del argumento gráfico}

A simple vista (y, desde luego, en fotos de aproximación y macro) se aprecian acciones fuertes del grabador retomando acá y allá lo trazado antes, hasta conseguir unos surcos anchos y profundos no muy regulares. Los cortes del instrumento lítico eliminan trozos no pequeños del asta (de hendidura notable y vértices no regularizados), se suceden sin orden aparente y no regularizan los trazos previos.

Al cubrir tanto repaso los rasgos previos de cada grafismo no es fácil precisar la secuencia de elaboración de todo el argumento, salvo en sus tres estadios básicos: primero, la obra de la moldura central; luego, la preparación de los dos campos laterales delimitados por esta moldura, eliminando por raspado la superficie cortical original del asta que ahí quedaba; finalmente, el trazado de las unidades gráficas curvilíneas. Las figuras 22a y 22b ofrecen una ampliación de las técnicas de grabado de los grafismos 14 y 15.

Con mínimos recursos ópticos (a partir de 5x) se comprueba que, en el campo izquierdo, unos cuantos trazos de los lados derechos de las unidades gráficas $(11,12,14,16)$ tocan el surco/límite izquierdo de la moldura central, invadiéndola; lo que, lógicamente y a la inversa, sucede en el campo derecho donde son los trazos de los lados izquierdos de sus unidades gráficas (D1, D2, D3, etc.) los que obliteran el surco derecho de la moldura. En el caso de un grafismo ovalado se pensaría que primero se hiciera el óvalo y luego el círculo acogido en su interior: el diseño del circulo (que quedó incompleto) de 15 y D6 se antoja una continuación - como al final y en prolongación - del trazado del óvalo correspondiente; pero, en otros casos, los trazos finales de círculos y óvalos (muchas veces repasados) enmascaran lo inicialmente dibujado (en secuencia ovalo-círculo: así D2, D5 etc.) dando ahora la apariencia inversa, como en 11 con trazos del óvalo superpuestos a los del círculo.

No es posible decidir en qué orden se trazaron las unidades gráficas y sus elementos: ¿primero las de uno 
de los campos y luego las del otro o entreveradas?, ¿empezando por abajo o por arriba o indistintamente?, ¿por uno de los dos tipos de grafismo (ovalado o serpentiforme) y reservando huecos para acoger los del otro?, etc.

Frente a la disposición más habitual del argumento curvilíneo o espiraliforme con unidades gráficas que ocupan, a "campo único", toda la superficie convexa de la varilla, este ejemplar de Ezkuzta ofrece el caso más excepcional de organización de dos campos alargados, como en "sólo tres varillas de Arudy cuyos motivos se disponen a un lado y otro de un eje longitudinal" (Saint-Perier, 1929: 54).

\subsection{Varilla 3}

\subsubsection{Descripción}

Prácticamente completa (faltan sus extremos distal y proximal), mide $181 \mathrm{~mm}$. de largo y completa, llegaría a alcanzar entre 200 y $210 \mathrm{~mm}$. Es de formato alargado, bastante estrecho (14,3 mm. de anchura) y algo grueso (espesor de 6,6 mm.) con sección transversal plano-convexa. Lo que se conserva de su extremo proximal sugiere que su base se acondicionó con biseles oblicuos a cada lado, mientras que su extremidad distal pudo estar apuntada (figuras 4 y 23).

\subsubsection{Análisis técnico y formal de las unidades gráficas}

Su superficie curvada está ocupada a campo total por un argumento constituido por tres grupos de unidades gráficas: unas líneas finas de diseño $(A)$, unos trazos grabados agrupadas en haces (B) y unos espacios no tratados (áreas reservadas, 'en blanco') (C) (figura 24).

Como los anchos y profundos surcos de las varillas 1 y 2, los más estrechos y superficiales de ésta resultan de repasados reiterados con puntas o filos líticos. Pero la finura (estrechez y limpieza) de todo lo grabado aquí y numerosos puntos de contacto entre los trazos (con recorte y superposición) permiten precisiones en el análisis de esta varilla que no se pudieron alcanzar en las otras dos.

A. El desarrollo argumental se asienta en algún tipo de encuadre y de diseño. La mayor parte de esta traza inicial quedó ocultada por los surcos de las posteriores unidades gráficas B salvo dos finas líneas (figura 25): la línea recta (u.g. A1) que recorre en sentido longitudinal parte del dorso y el trazo curvado (u.g. A2) que delimita parte del espacio en blanco C5.

B. Hay diez unidades gráficas (figura 26) de líneas profundas largas paralelas agrupadas en haces. Para ilustración se amplian las zonas distal (figuras 27a y $27 b$ ), central (figuras $28 a$ y 28b) y proximal inferior (figuras 29a y 29b) de la varilla.
La u.g. B1 está formada por once líneas ondulantes en dirección arriba-derecha a abajo-centro y ocupa buena parte (inferior del tercio superior y todo el tercio medio) de la banda central del dorso de la varilla. El extremo inferior de las cuatro líneas de su lado derecho se curva (con parcial rectificación de su delineación inicial) hasta alcanzar (y articularse en ángulo agudo con) la anexa B3. Las líneas del haz B1 son parte llamativa del eje decorativo del tema; esta u.g articula las otras u.g. de la mitad distal del soporte; las líneas de la derecha e izquierda de B1 delimitan respectivamente los contiguos espacios reservados C3 y C4.

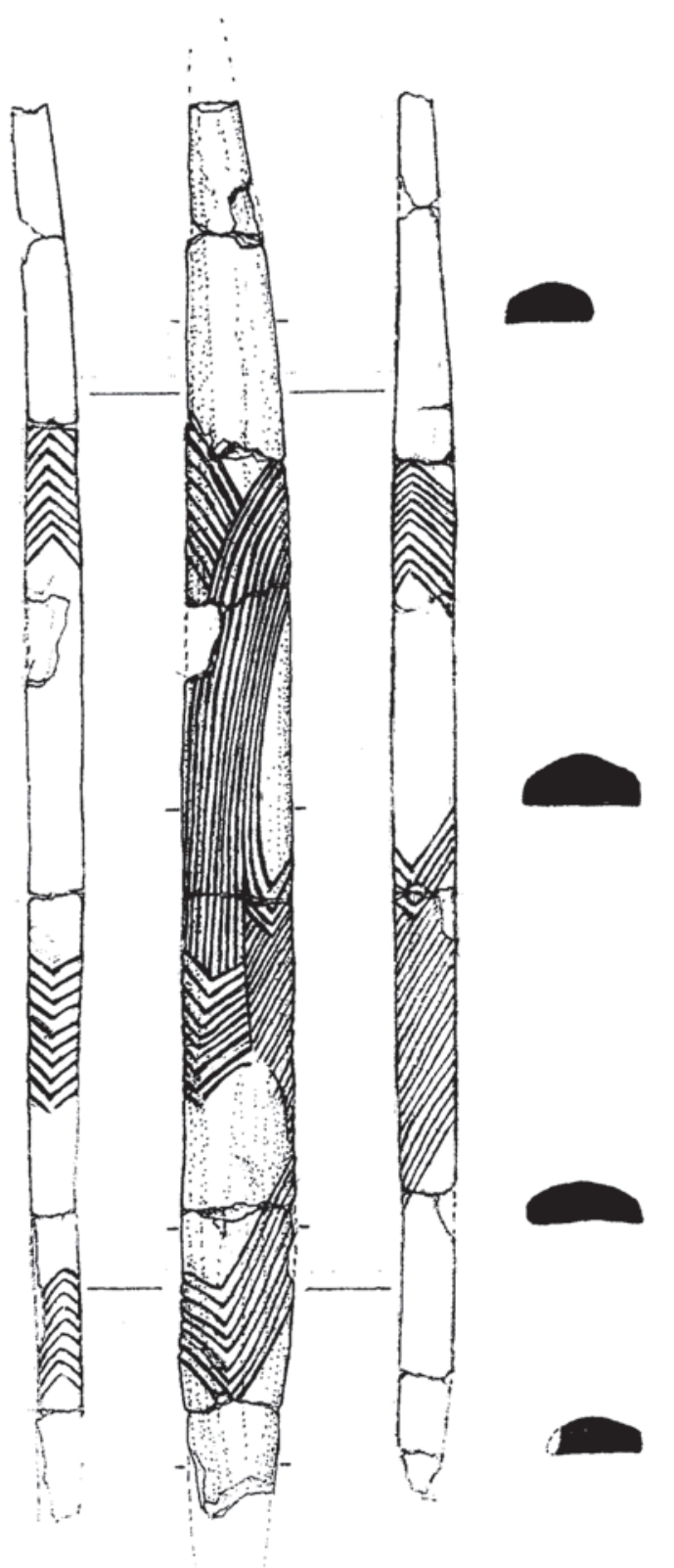

Fig. 23. Varilla 3: vistas lateral izquierda, dorsal y lateral derecha y secciones transversas. / Rod 3: left side, dorsal and right side views and cross sections. 


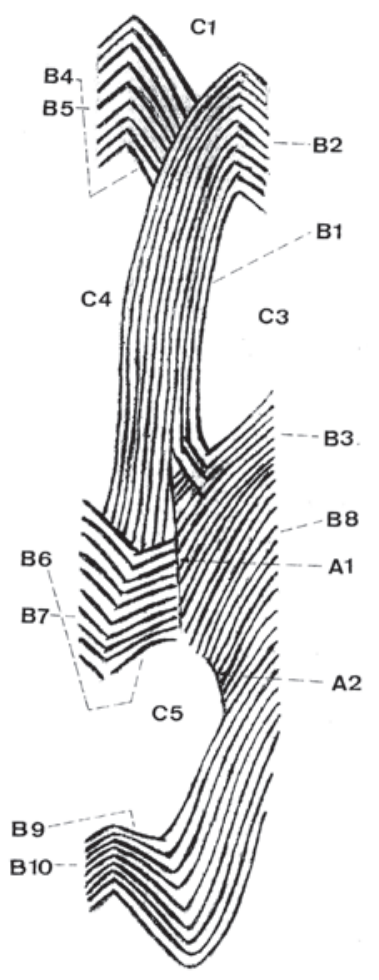

Fig. 24. Varilla 3: síntesis de su argumento gráfico en líneas de delimitación de campos (A) trazos agrupados en haces (B) y áreas reservadas (C). I Rod 3: synthesis of its graphic argument in lines of delimitation of fields (A), traces grouped in beams (B) and reserved areas (C).

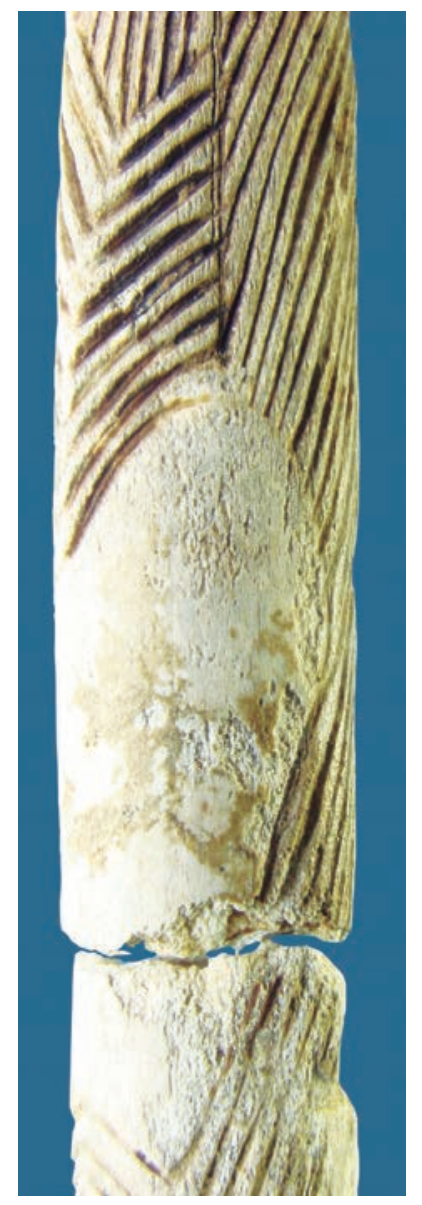

Fig. 25. Varilla 3: detalle del dorso de la zona proximal con las líneas 'de esbozo' A grabados anchos y profundos B: la recta vertical A1 (arriba, en el centro de la imagen) marca el eje central del dorso a decorar y la curvada A2 (centro derecha de la imagen) delimita parte del espacio reservado C5. / Rod 3: detail of the back of the proximal area with the 'outline' lines A wide and deep engravings $B$. the vertical line $A 1$ (above, in the center of the image) marks the central axis of the back to decorate, and the curved A2 (center right of the image) defines part of the reserved space C5.

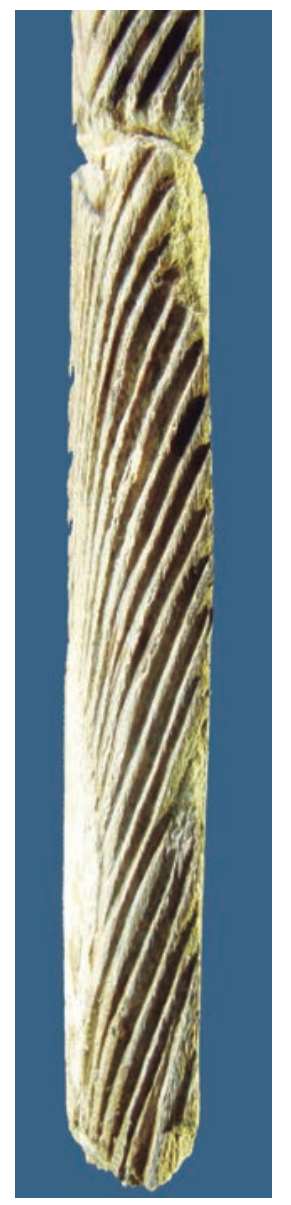

Fig. 26. Varilla 3: haces B3 (parte baja) y B8, sobre el costado derecho de la zona proximal de la varilla, orientado su trazado en sentido arriba derecho a abajo izquierdo. / Rod 3: beams B3 (lower part) and B8, on the right side of the proximal area of the rod, oriented its path in the upper right to lower left direction.
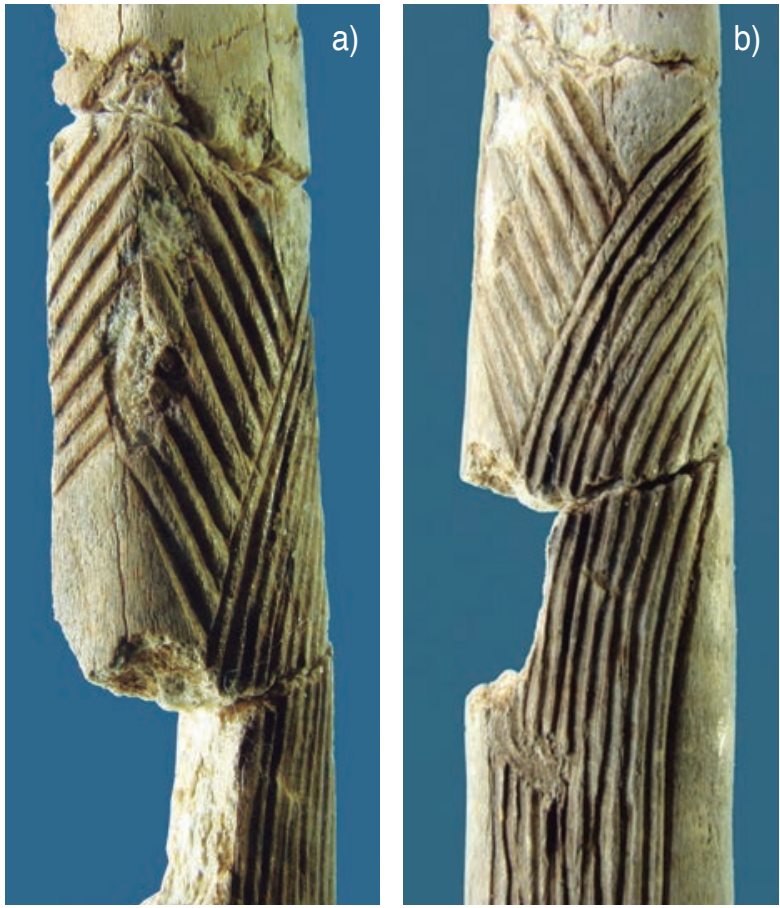

Fig. 27. Varilla 3: detalles ampliados del tercio distal desde los lados izquierdo a) y derecho b). / Rod 3: enlarged details of the distal third from the left $\mathbf{a}$ ) and right $\mathbf{b}$ ) sides.
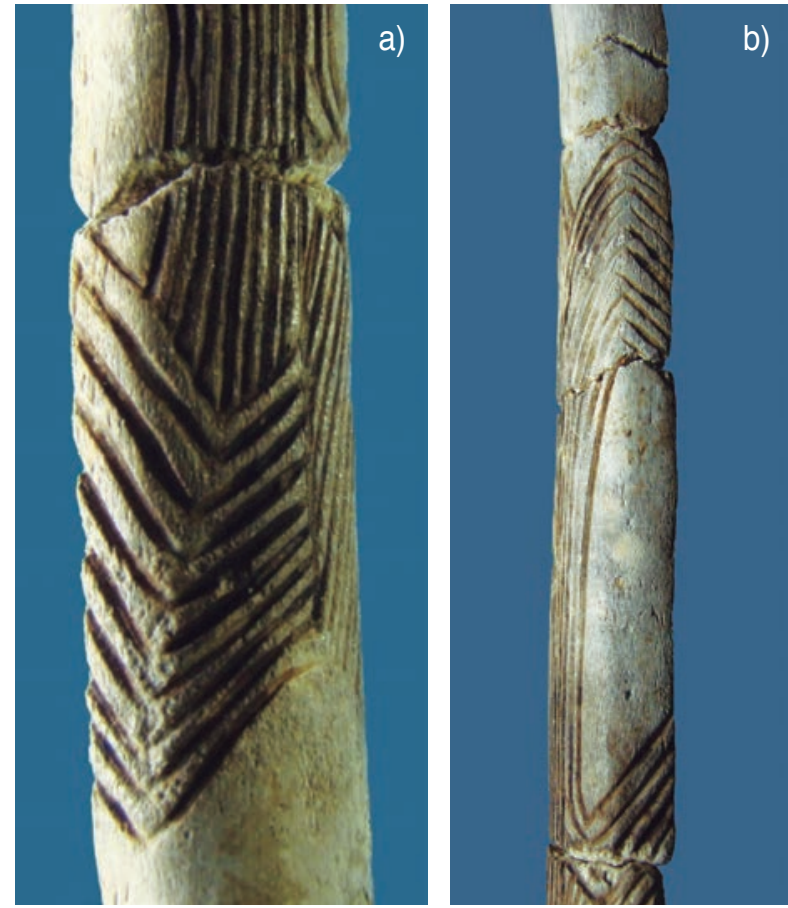

Fig. 28. Varilla 3: detalles ampliados del tercio central desde los lados izquierdo a) y derecho b). / Rod 3: enlarged details of the central third from the left $\mathbf{a}$ ) and right $\mathbf{b}$ ) sides. 


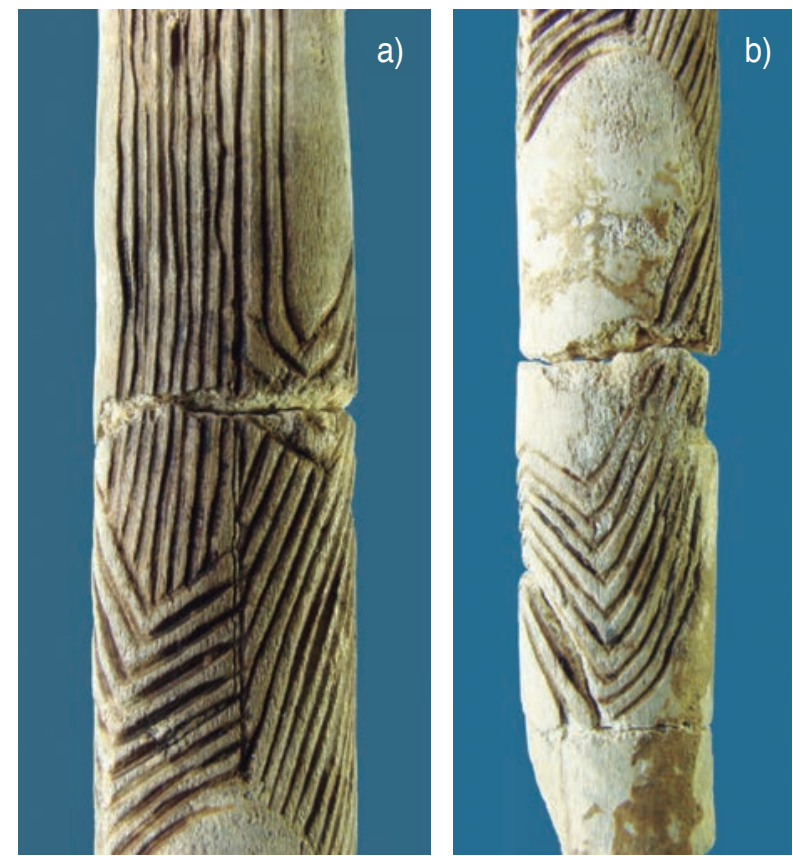

Fig. 29. Varilla 3: detalles ampliados de los tercios central a) y proximal b) / Rod 3: enlarged details of the central a) and proximal b) thirds.

B2 consta de once líneas cortas en oblicuo (arriba-izquierda a abajo-derecha) sobre una estrecha banda del costado derecho del dorso e inmediata zona achaflanada del tercio distal de la varilla. Las partes superiores de las líneas B2 confluyen en ángulo agudo (vértice arriba) con los extremos superiores de las B1.

B3 son cuatro líneas no largas en oblicuo (arriba-derecha a abajo-izquierda), sobre el costado derecho -zona central- del dorso de la varilla. Como en B2, las líneas de B3 confluyen en ángulo muy agudo (vértice abajo) con las cuatro líneas del lado derecho (parte baja) de B1. La convergencia de las unidades gráficas B1, B2 y B3 delimita buena parte del espacio C3 (la línea que cerraría esa superficie oblonga 'en blanco' viene suplida por el vértice de confluencia de las caras dorsal y ventral en el lado derecho de la varilla).

B4 es un haz de nueve líneas no largas en oblicuo (arriba-izquierda a abajo-derecha) sobre la banda dorsal izquierda de la varilla: sus líneas tocan a las de las contiguas u.g. B1 y B5 (los extremos inferiores de las nueve incisiones de B4 acaban en la incisión lateral izquierda de B1; sus extremos superiores convergen en ángulo semiagudo -vértice arriba- con las nueve líneas de B5 -en oblicuo abajo-izquierda a arriba-derecha-). La u.g. B5 es similar a la B4, con la que converge, articulándose ambas en ángulo.

B6 y B7 son relativamente similares (cada una con diez líneas de longitudes varias) combinadas y ubicadas en oblicuo: B6 de arriba-derecha a abajo-izquierda y B7 de arriba-izquierda a abajo-derecha, convergentes entre sí (en ángulo abierto con el vértice hacia abajo). El par B6+B7, en disposición opuesta a la del par precedente $\mathrm{B} 4+\mathrm{B} 5$, delimita con éste, pero por su parte inferior, el polo inferior del espacio C4; además ese par B6+B7 limita por arriba el espacio C5.

B8 es un haz de veinticinco líneas oblicuas (arriba-derecha a abajo-izquierda) sobre la mitad proximal de la varilla. Los límites de las quince líneas superiores de esta u.g. vienen dados por las líneas sencillas de las A1 (recta, de arriba abajo) y A2 (curvada). B8 organiza la distribución de los grafismos de toda la mitad inferior del tema: sus (una o) dos primeras líneas muy cortas rellenan el espacio que media en la bifurcación inferior de B1; las (seis o) cinco líneas cortas a medianamente largas (partiendo de la vertical A1) "se enfrentan" a las unidades B6+B7; las (ocho o) nueve líneas de longitud media (desde el límite de la curvada A2) "rodean" el cuarto derecho superior del espacio C5; y (nueve u) ocho líneas bastante largas completan la parte derecha del espacio ese mismo C5 y se articulan en su extremidad inferior con el inmediato par B9+B10.

B9 y B10 están formadas por líneas emparentables (cortas a medianas en B9 y muy cortas en B10): las nueve de cada una de ellas convergen entre sí en ángulo (vértice hacia arriba); los extremos inferiores de las nueve líneas inferiores de B8 convergen en los extremos inferiores de B9 en ángulo agudo (vértice hacia abajo).

Son similares las articulaciones de bastantes de estas unidades gráficas con forma de ángulo: parte superior de B1 con B2; parte inferior derecha de B1 con B3; parte inferior izquierda de B1 con B7; B6 con B7; parte inferior de B8 con B9; B9 con B10. Todas tienen un fin compartido: delimitar, por arriba y abajo, los tres espacios reservados C3, C4 y C5.

C. Cinco áreas reservadas ('en blanco') se ubican con cierta simetría por la superficie dorsal de la varilla. Las C1 y C2 acotan la "decoración" por los dos extremos de la varilla: mayor el espacio distal C1 que el proximal C2. Las C3, C4 y C5 se integran en el argumento al quedar rodeadas en las tres cuartas partes de sus áreas) por los haces de líneas (u.g. B): C3 y C4 tienen forma subovalada alargada y se disponen a uno y otro lado del tercio medial de la varilla; C5 es subcircular y ocupa el centro del tercio proximal.

\subsubsection{Trazado y estructura del argumento}

En fotos macro (de 20x a 40x) (figuras 30a, 30b, 30c, 30d y 30e) se aprecian repasos en el interior de cada surco mediante incisiones muy finas (someras y, sobre todo, estrechas) hasta alcanzar su presentación final (profunda y no muy ancha) testificando el curso de su trabajo.

Bastantes de las líneas de dirección oblicua marchan desde el borde de la varilla hacia su centro. Los pares en ángulo B6+B7 y B9+B10 (situados en la banda izquierda del tema) se trazaron desde el lado izquierdo del soporte hacia su centro; y se prolongan en ese 

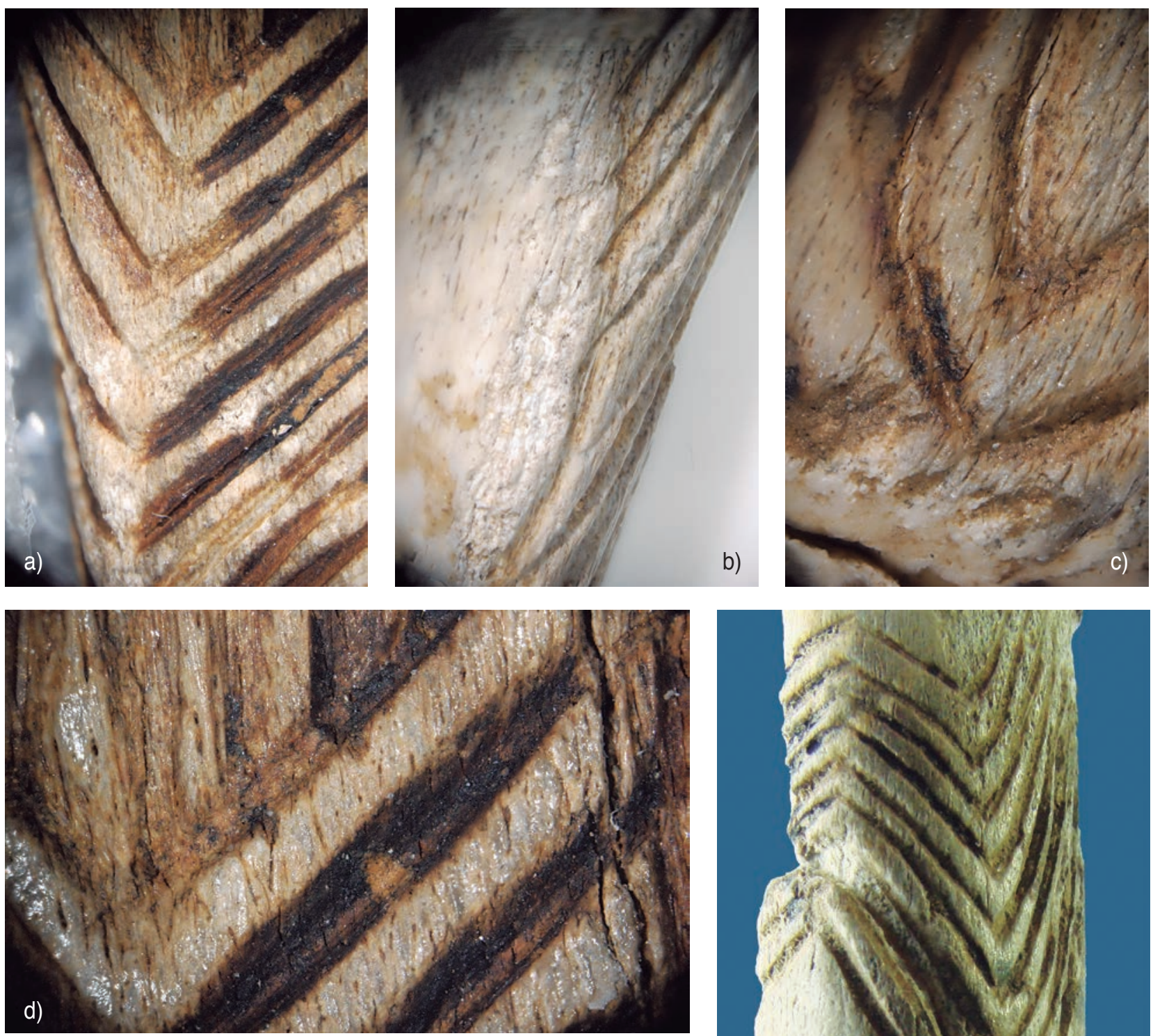

Fig. 30. Varilla 3: detalles ampliados de las unidades gráficas de las zonas central e inferior: a y $\mathbf{d}$, yuxtaposición, recubrimiento y repaso de incisiones finas someras hasta conformar trazos profundos (convergencia de B6 y B7); b, superposición del extremo de algunos surcos de la unidad B8 sobre la línea curvada de esbozo A2; c, repasos de los trazos convergentes en ángulo de partes de B1 y B3 (que delimitan el extremo inferior del espacio C3) que llegan confundir el orden de su ejecución; $\mathbf{d}$, trazado final del surco superior B7+B6 que corta, superponiéndoseles, los grabados de la parte baja del haz B1; e: detalle del extremo inferior. / Rod 3: enlarged details of the graphic units of the central and lower zones: $\mathbf{a}$ and $\mathbf{d}$, juxtaposition, coating and review of shallow thin incisions until forming deep lines (convergence of B6 and B7); $\mathbf{b}$, superposition of the end of some grooves of unit B8 on the curved outline line A2; c, reviews of the convergent angled lines of parts of B1 and B3 (which delimit the lower end of spa$\mathrm{ce} \mathrm{C3}$ ) that confuse the order of their execution; $\mathbf{d}$, final tracing of the upper groove B7 + B6 that cuts, overlapping, the engravings of the lower part of the B1 beam; e: detail of the lower end.

mismo sentido izquierdo/derecho B7 (izquierda arriba a derecha abajo) con B6 (izquierda abajo a derecha) y B10 (de abajo izquierda) con B8 (arriba izquierda a abajo derecha). Del mismo modo (pero a la inversa) también se trazarían desde el borde hacia el centro (en este caso de derecha a izquierda) las líneas oblicuas de la B8, situada en la banda izquierda del tema.

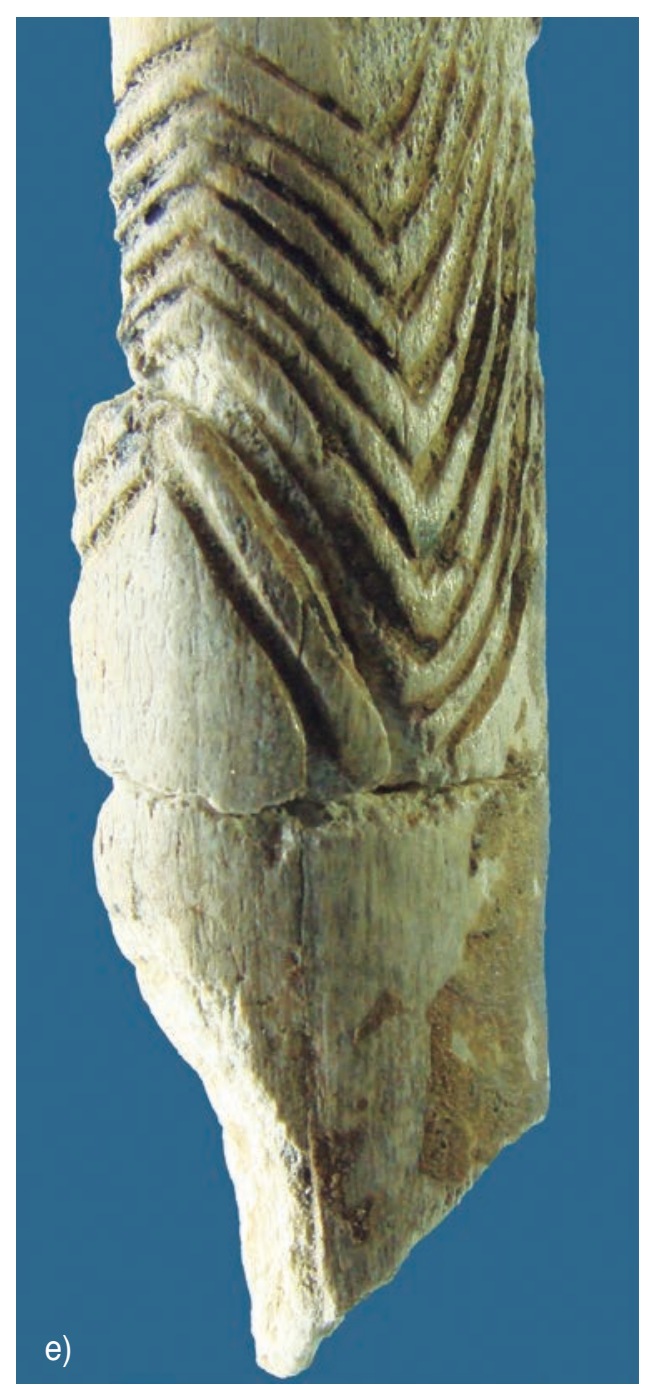


Una discusión sobre la secuencia de lo trazado en esas u.g. partiría del apriorismo discutible, desde luego- de que habrían sido concebidas por sus autores como un conjunto y, por tanto, se habrían elaborado en "coetaneidad". Sistemáticas obliteraciones de trazos previos por posteriores rasparon tan reiteradamente la mayoría de los puntos donde se ponen en contacto líneas en direcciones distintas que no es posible decidir el orden de su trazado. En algún caso en que se descuidó ese acabado final, quedando rebabas de pasadas anteriores del grabador, se han conservado zonas (habitualmente las de las extremidades de los trazos) que permiten decidir el orden de ejecución de parte de esas líneas. En los casos de quince de esas intersecciones y contactos entre u.g (A1-B1, A1-B6, A1-B8, A1-A2, A2-B8, B1-B2, B1-B3, B1-B4, B1-B6+B7, B4-B5, B6-B7, B8-B3, B8-B6, B8-B9 y B9-B10):

- el repaso final de la parte inferior de la línea tercera por la derecha de B1 parece superponerse al extremo superior de A1.

- el repaso último de A1 corta los finales de las partes inferiores de algunas de las líneas B6 (véase su detalle a ×20 en la figura 30a).

- no se puede decidir si el inicio, por la izquierda, de las líneas de la parte superior de B8 atraviesa o no el trazo A1.

- no se aprecia contacto entre las líneas finas A1 y A2, por lo que no se puede reconocer el orden de su trazado.

- el último repaso del extremo de algunas de las líneas oblicuas de la parte central de B8 pasa por encima de la línea curvada A2 (véase su detalle a x30 en la figura 30b).

- es probable, pero no seguro, que B2 sea posterior a B1.

- es posible que las cuatro líneas del lado derecho de B1 sean anteriores a las incidentes en la parte baja de B3 (detalle a x40 en la figura 30c.

- el repaso de la línea izquierda B1 corta limpiamente los extremos inferiores de algunas de B4.

- la última traza de la línea superior del par B6+B7 pasa sobre la parte inferior de algunas de las líneas longitudinales de B1 (detalle a x40 en la figura 30d).

- el trazado de enmienda que endereza la confluencia de la parte inferior de B1/B3 parece cortar las líneas superiores de B8.

- es probable (no seguro) que los puntos de incidencia de las partes superiores de las nueve líneas de B5 se superpongan a correspondientes de B4.

- el último repaso de algunas líneas de B6 cubre los puntos de su articulación en ángulo con algunas de B7.

- careciéndose de puntos de contacto entre B6 y B8 no se puede decidir el orden de su trazado.

- tampoco puedo determinar el orden de ejecución de B8-B9 y B9-B10 por ser reiterados y en sentidos opuestos los repasos de las líneas trazadas en las zonas de convergencia en ángulo entre ellos.

En síntesis, el argumento que cubre esta varilla a campo total se compone de espacios reservados subovales $\mathrm{C}$ (ubicados con simetría sobre la superficie disponible, sirviendo C1 y C2 para enmarcar el conjunto por ambos extremos) a los que cercan los haces de líneas B. En su puesta en obra se sucedieron dos etapas: primera, la del diseño de todo mediante incisiones muy finas (u.g. A), de las que ahora quedan a la vista sólo alguna de las que marcan el eje central del argumento (A1) o delimitan los espacios a reservar (A2), y luego, la de ejecución de tres de esos juegos espacio reservado+haces (C3 y su entorno $\mathrm{B} 2+\mathrm{B} 1+\mathrm{B} 3, \mathrm{C} 4 \mathrm{y}$ $\mathrm{B} 5+\mathrm{B} 4+\mathrm{B} 1+\mathrm{B} 7, \mathrm{C} 5$ y $\mathrm{B} 7+\mathrm{B} 6+\mathrm{B} 8+\mathrm{B} 9+\mathrm{B} 10)$ dispuestos simétricamente (los dos primeros a un lado y otro de la mitad superior de la varilla, el tercero en la parte axial de su tercio inferior).

\section{ANÁLISIS DE LAS VARILLAS DE EZKUZTA 4.1. Dispositivos "característicos" en las vari- Ilas del Magdaleniense medio pirenaico}

Saint-Périer) de niveles del Magdaleniense medio en el espacio pirenaico francés recogieron varillas decoradas a campo completo con tres tipos de trazado: los grabados curvilíneos (espiraliformes o sinuosos) con los consiguientes/anexos temas "en relieve"; los grabados cortos simétricos longitudinales y los grabados en haces combinados con espacios reservados.

\subsubsection{Grabados curvilíneos}

Los grabados curvilíneos (espiraliformes o sinuosos) son "decoración peculiar y homogénea constituida por motivos geométricos complejos curvilíneos, grabados o más a menudo esculpidos en relieve fuerte a lo largo de toda la superficie convexa" (Saint-Périer, 1939: 263).

Entre otros prototipos industriales y tratamientos gráficos éstos también fueron aflorados (= extraídos de un yacimiento e identificados con seguridad) por E. Piette al presentar en 1894 tres varillas: una con 'volutas' que encontró en Espalungue/Arudy y dos que halló $L$. Nelli en Espélugues/Lourdes, de 'círculos con relieve central' y con 'temas retorcidos' (torsades). Una década más tarde E. Piette catalogó ya diez varillas (Piette, 1904: figs. 7, 8 y 19-26 dibujadas por H. Breuil): cinco de Arudy y cinco de Lourdes (figura 31).

En la excavación 1909/1910 de Hornos de la Peña (Cantabria), dirigida por J. Bouyssonie, se halló un fragmento de varilla decorada que se relacionó con las de Arudy y Lourdes (Breuil y Obermaier, 1912: 8). Según P. Saint-Périer (1929: 55-56 y fig.9), I. Barandiarán (1972: 134 y fig. 9.2 y lám. 27.4) y S. Corchón (1986: 302 y fig. 57.1) el grabado que cubre la cara dorsal de esta varilla de sección planoconvexa está dispuesto en giros y ondulaciones que recuerdan la cabeza de un toro. 


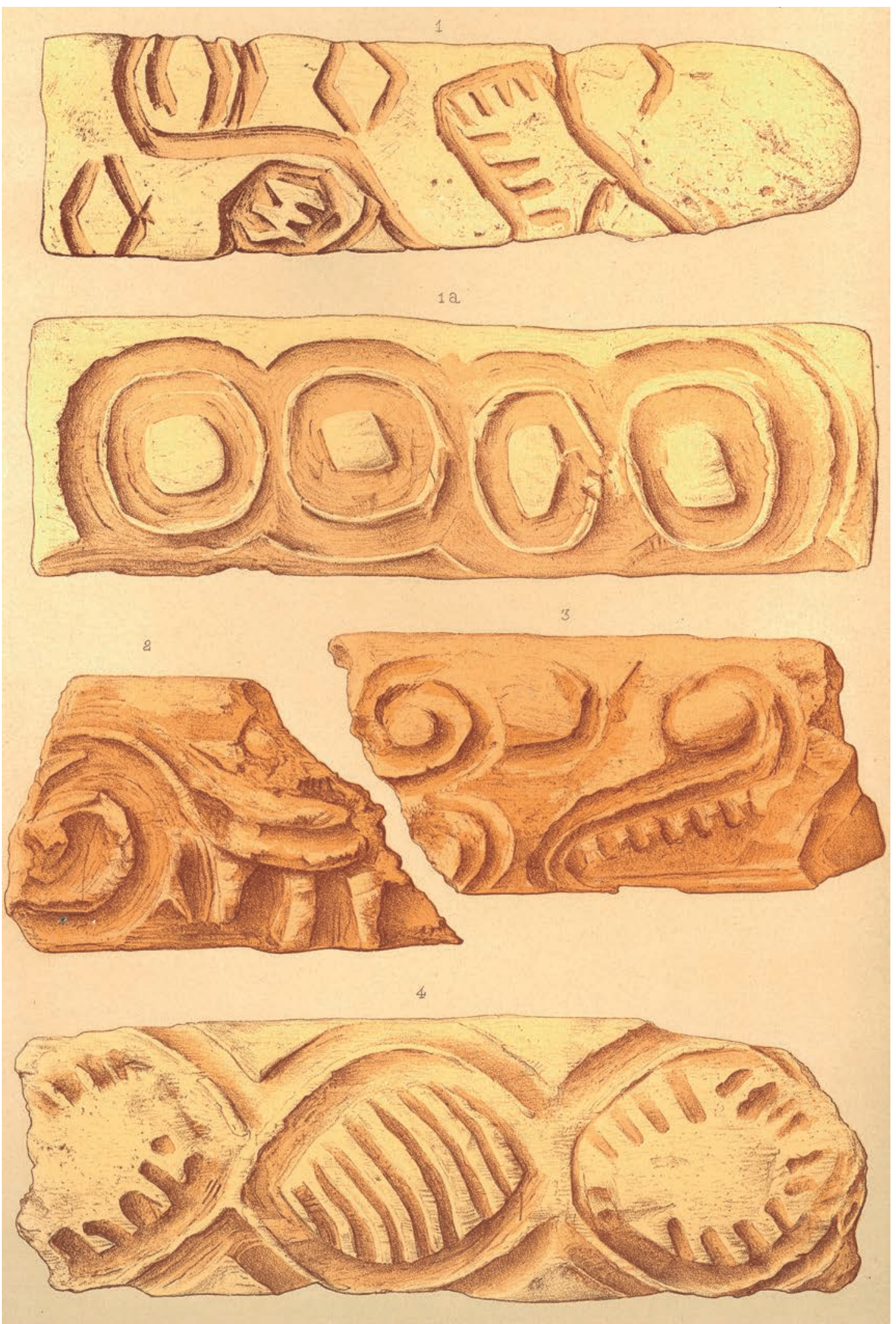

Fig. 31. Decoraciones curvilíneas (espiraliformes, en volutas, etc.), como las de las varillas 1 y 2 de Ezkuzta, sobre fragmentos de cinco ejemplares de Espélugues/Lourdes en interpretación de J.Pilloy (tomadas de E.Piette 1907). / Curvilinear decorations (spiral, in scrolls, etc.), such as those of rods 1 and 2 of Ezkuzta, on fragments of five specimens of Espélugues / Lourdes in interpretation of J. Pilloy (taken from E.Piette 1907). 
Las excavaciones en las cuevas de Harpons/Lespugue por R. de Saint-Périer (1913-1914) y de Isturitz por E. Passemard (1913-1916, 1920-1922) y por R. de Saint-Périer (1928-1939, 1941, 1942, 1946-1949, 1951, 1952) aportaron la mayor cantidad de ejemplares (figura 32).

R. de Saint-Périer presentó (1920: 227-228 y fig.8) fragmentos de cinco varillas de Lespugue: "esculturas en espirales, en círculo y en festón talmente semejantes a las de piezas análogas encontradas antes que uno tiene derecho a pensar que estos objetos admirables hubieran sido obra de un solo y mismo operario". Se encontraron en el nivel B que yacía entre los contiguos infrapuesto C (Magdaleniense "antiguo"), y superpues-
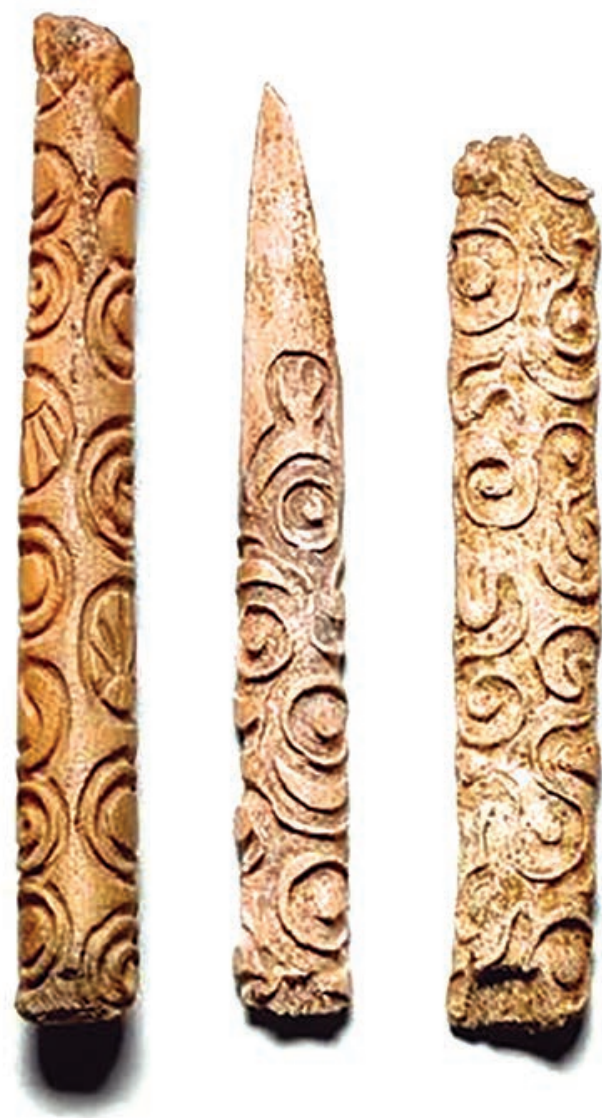

Fig. 32. Decoraciones curvilíneas (espiraliformes, en volutas, etc.), como las de las varillas 1 y 2 de Ezkuzta, sobre varillas de Isturitz/col. Saint-Périer en fotografía de J.Vertut (tomadas de A. Leroi-Gourhan 1965). / Curvilinear decorations (spiral, in scrolls, etc.), such as those of rods 1 and 2 of Ezkuzta, on rods of Isturitz / col. Saint-Périer in photograph by J. Vertut (taken from A. Leroi-Gourhan 1965). to A (Magdaleniense avanzado con algún arpón de dos hileras de dientes y otro de cierta aparencia aziloide). De similar procedencia son otros dos fragmentos de varillas hallados en 1927 (Saint-Périer, 1929: figs. 1-2).

Fueron cuatro las piezas que encontró E. Passemard (1920: 150-152 y fig.1) en el nivel E de Isturitz: "especie de disco rodeado de un surco", "espiral simple y curva en forma de 6 como las tres piezas principales de Arudy", "la más bella con todos los motivos de Lourdes y Arudy salvo las espirales" y un pequeño fragmento, "grabado simplemente en surco estrecho profundo... que es un poco más reciente y debe pertenecer a una época en que se ponía menos cuidado en la ejecución de objetos similares".

R. de Saint-Périer (1929: 43-55 y 60-62) agrupó el efectivo entonces conocido de decoraciones curvilíneas en dos lotes: espirales esculpidas más propias del ámbito magdaleniense pirenaico (veintitres casos: cinco de Arudy -cuatro recogidas por E. Piette y una quinta por Mr. Potier, siete de Lourdes -seis de la colección L.Nelli y otra recuperada por Mr.Telhac -, siete de Lespugue y las cuatro de Isturitz -excavación de Passemard-) y espirales grabadas (de surcos menos profundos y menos anchos, sin destacar filetes en relieve entre ellos) que en contadísimos casos se extienden a espacios más lejanos y a otros soportes (una azagaya de Bruniquel, astas perforadas o no de Conduché y Laugerie Haute, la varilla citada de Hornos de la Peña etc.). Y se discutió su datación: nada determinantes las condiciones estratigráficas de Arudy y, menos aún, las de Lourdes (colleción Nelli); las piezas de Lespugue son "de una edad todavía antigua del Magdaleniense pero no del Magdaleniense más antiguo de los Pirineos"; las de Passemard en Isturitz en el nivel E integrado por varios depósitos magdalenienses "anteriores todos al Magdaleniense con arpones". Además (ibid., 54-60 y figs. 8-12) descompuso los argumentos gráficos asentados en esas varillas en sus concretos "motivos decorativos... para reconocer sus semejanzas" y, conseguida su correcta tipología, organizó estas unidades gráficas en una decena de grupos "que hacen más evidente tanto su variedad como la homogeneidad de esa decoración"2.

Al presentar (Saint-Périer, 1930: 102-104) dos fragmentos de varillas encontrados en su excavación de la sala St. Martin de Isturitz asentó el tópico asumido con unanimidad por la Arqueología posterior: su pertenencia al "grupo muy homogéneo y hasta ahora ex-

\footnotetext{
2 Se trata de unidades gráficas: en espiral simple, el tema más llamativo (Saint-Périer 1929, figs. 8.1-25). Aquí incluidos los grabados en espiral que sugieren la forma de una cabeza de bovino de Hornos de la Peña; unidades gráficas en S con dos espirales opuestas juntas (ibid., figs. 8.21-29), como en la varilla 2 de Ezkuzta; unidades gráficas en sierra con dientes, que acompañan habitualmente a motivos circulares o curvados serpentiformes (ibid., figs, 10.1-13), como en la varilla 1 de Ezkuzta; unidades gráficas en círculo o disco con variantes (p.e. poligonales) (ibid., figs. 11, 27-51), como en la varilla 1 de Ezkuzta; unidades gráficas en curva serpentiforme; unidades gráficas en óvalo bicóncavo con variantes (entre ellas, el almendrado) (ibid., figs. 11.61-67), como en la varilla 2 de Ezkuzta; unidades gráficas en creciente; unidades gráficas en trifurcado (muy escasos); unidades gráficas sencillas (en espina, en S, en disco, en óvalo, etc.) sueltas, en serie o incorporadas a otros; unidades gráficas 'pectiniforme' (como brazos paralelos o divergentes adosados a un círculo) (ibid., fig.12).
} 
clusivamente pirenaico de las esculpidas 'con espirales'3. La mayor colección fue encontrada por él mismo (Saint-Périer, 1936: 86-92 con dibujos de buena parte de ellas en figs. 51-53) en la Gran Sala de Isturitz: veintinueve fragmentos (más o menos grandes) de varillas (en mayoría de sección semicilíndrica, algunas de sección subcircular) con "decoración esencialmente curvilínea con espirales" y temas "vecinos". Ahí precisó técnicas de elaboración de surcos/esculturas y variantes de temas, discutió sobre función y significado del grafismo y planteó una interrogante sobre la causa de su común estado de fragmentación. En su opinión, parecería que "por constante que sea, no debió ser intencional, puesto que las fracturas ofrecen exactamente el mismo aspecto que el de gran número de las varillas semicilíndricas no decoradas, por lo que se debería a la forma de las piezas. Aunque una experiencia que hicimos con una lámina de hueso del mismo espesor nos permite asegurar que hace falta un gran esfuerzo para romperla; presentando la fractura una forma alargada comparable a la de nuestras varillas. De lo que se puede concluir que las varillas esculpidas o no esculpidas parecen haber sido sometidas a la misma causa de ruptura y que ésta había sido violenta" (Saint-Périer, 1936: 91-92).

Por fin, recopiló Saint-Périer (1939: 264-269) su parecer sobre la referencia cronocultural del lote de Isturitz que "pertenece al Magdaleniense IV, es decir al período más rico y más variado en obras de arte de todo el Magdaleniense"; y sobre su origen decididamente pirenaico, "que pudiera atribuirse a Isturitz o a Lespugue... si se tiene en cuenta el número de esas piezas y la belleza de su ejecución..., y que no han aparecido hasta ahora en otros sitios de la misma región, salvo Lourdes y Arudy". Y, en lógica argumental, "su extensión que parece haber sido tan breve en el tiempo como limitada en el espacio" y su autoría compartida pues "la inspiración de una tribu pirenaica ha promovido (presidé) su ejecución".

La misma opinión de los espiraliformes de Isturitz (desde la última presentación sintética de su antología en Saint-Périer, 1939: fig.1) se irá repitiendo, con no mucha renuencia, en referencias posteriores al conjunto del arte paleolítico occidental (Graziosi, 1960: láms. 94-95 -asumiendo en blanco y negro las ilustraciones de Saint-Périer-, Zervos, 1959: fig. 277 -fotografías en blanco/negro de C. Hurault-, Leroi-Gourhan, 1965: láms. 38-44 -fotografías en color de J. Vertut-, etc.). Desde mediado el siglo XX se han presentado otros contados testimonios de esta clase de varillas: sendos fragmentos del Mas d'Azil (Chollot, 1964: 342-343), Duruthy/ Sorde (Arambourou et al 1978: fig. 20) y Espélugues/ Lourdes $^{4}$, tres de Bourrouilla/Arancou (Fritz y Roussot, 1999: fig. 28) y la pieza completa de Poggenwisch (Bosinski, 1978)5. La excavación de Ezkuzta aporta dos nuevos ejemplares: los fragmentos de la varilla 1 y la prácticamente completa 2.

Suman así en el catálogo total de estas varillas (casi todas fragmentos) sesenta y tres (¿hasta sesenta y cinco?) ejemplares. Situadas sobre un mapa (Bosinski, 1982: 52) destacan absolutamente (con el 95,2\%) las del Pirineo (de oeste a este: tres en Bourrouilla, una en Duruthy, treinta y cinco en Isturitz, cinco en Arudy, ocho en Lourdes, siete en Lespugue y una en Mas d'Azil) con presencia puntual en otras zonas a media distancia hacia el oeste (las dos de Ezkuzta y una en Hornos de la Peña) o en el remoto bajo Elba (una en Poggenwisch, al norte de Alemania) (figura 33). No se incluye la presencia de grafismos más o menos similares realizados sobre no-varillas en sitios del sudoeste francés como una azagaya de Bruniquel, astas perforadas o no de Conduché y Laugerie Haute, etc., más alguna referencia nominal que no se ha conseguido comprobar.

\subsubsection{Grabados complejos longitudinales simétricos}

Los grabados curvilíneos (espiraliformes o sinuosos) son Este tipo de grabados son "dispositivos axiales o longitudinales, de muescas laterales, crecientes, incisiones cortas, paréntesis, etc." (Feruglio, 1998: 191-192) (figura 34).

En 1913 recuperó E. Passemard en el nivel E de Isturitz (Magdaleniense medio) dos varillas de sección semicilíndrica que suscitaron su atención: por su excelente conservación y tamaño excepcional (prácticamente enteras con 370 a 380 mm. de longitud por 12 de anchura); por la identidad gráfica entre las dos (temas en hileras longitudinales en los dos lados del soporte) $)^{6}$ y por la alta probabilidad, muy bien argumentada, de que se hubieran empleado las dos adosadas por sus caras plana para "formar una sola y misma varilla cilíndrica" (Passemard, 1916). Excavando de seguido en el mismo lugar, E. Passemard amplió el repertorio de este tipo de deco-

\footnotetext{
${ }^{3}$ Y, recuperando la referencia etnográfica de G.A. Montandon a varillas decoradas usadas en cultos de los Aïnos, con "la hipótesis de un uso de tipo religioso como bastante satisfactoria dada la importancia del trabajo que representa la decoración de esas varillas, pero puede que sea insuficiente para explicar la preocupación artística que parecen revelar".

${ }^{4}$ Notificada inicialmente como de Massat (por R. de Saint-Périer en 1957), ha sido convenientemente reducida (en un catálogo de J. Omnès de 1980, apud Fritz y Roussot, 1999: 55-56) a su real procedencia de antiguas excavaciones en Espélugues/Lourdes.

5 Su clasificación (Bosinski, 1978 y 1982: 48) como stab (genérico al. traducible como bastón, vara, barrote etc. en español y así vertido al fr. bâton en Bosinski 1990, 251-252) dejando de lado su "diminutivo" stäbchen (= fr. baguette; esp. varilla, palillo, listón) acaso pretendía remarcar lo peculiar del ejemplar alemán (de un sitio tan alejado y de un exótico nivel hamburguiense) con respecto al inventario de las decenas de "varillas" magdaleniense pirenaicas dotadas de grafismos curvilíneos (en lo que sí coincide, de cierto, la pieza de Poggenwisch).

${ }^{6}$ Integrado cada uno de esos longitudinales por arcos alargados adosados en línea, separados cada uno del contiguo por un trazo corto perpendicular y rematada la serie en su extremo inferior por signos en flecha de vástago corto ("en trébol") también en posición perpendicular.
} 


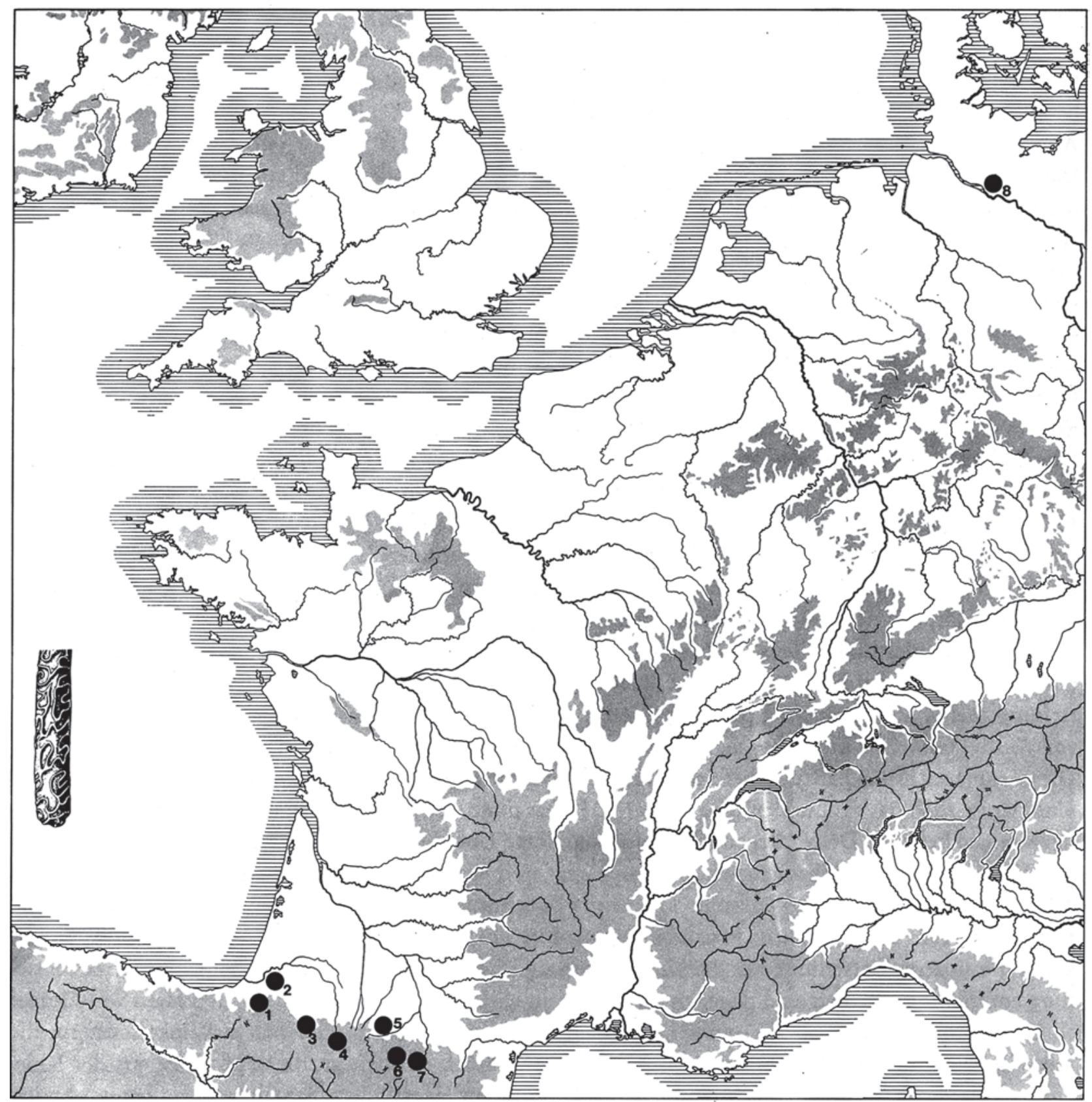

Fig. 33. Cuadro de dispersión de las varillas con decoración espiraliforme-curvilínea (al margen el particular ejemplar de Poggenwisch), como la de los ejemplares 1 y 2 de Ezkuzta (tomado de G. Bosinski 1982). / Table of dispersion of the rods with spiral-curvilinear decoration (apart from the particular example of Poggenwisch), such as that of rods 1 and 2 of Ezkuzta (taken from G. Bosinski 1982).

ración, avanzando la identificación de los temas (Passemard, 1920) y sintetizándolos al fin en un cuadro con sus principales variantes (Passemard, 1944: 65-66). La excavación del nivel II de la Gran Sala de Isturitz por R. de Saint-Périer (1936: 78-84 y figs. 46-47) recuperó, sin cuantificarlas, varillas de sección semicilíndrica con un "arte ornamental", "sin ninguna inspiración naturalista... con gran variedad de adornos de aspecto geométrico... ángulos en el centro del fuste, zigzags, ahusados, medios husos a lo largo entre los que se intercalan pequeños motivos en flecha...".
Son relativamente frecuentes en la ecúmene magdaleniense del sudoeste de Europa, con presencia nodal en el Magdaleniense medio extendida, a veces, a una situación cultural inmediatamente posterior. Por ejemplo, las dos halladas en el nivel A (final del Magdaleniense) de Harpons/Lespugue (Saint-Périer, 1920: figs. 2.6 y 2.7) o las que se recuperaron en el nivel intermedio (dotado ya con arpones de una hilera de dientes) del sitio epónimo (Capitan y Peyrony, 1928: figs. 40.6, 40.7, 40.1 y 42.2), es decir, en el estadio prototípico del Magdaleniense superior. 


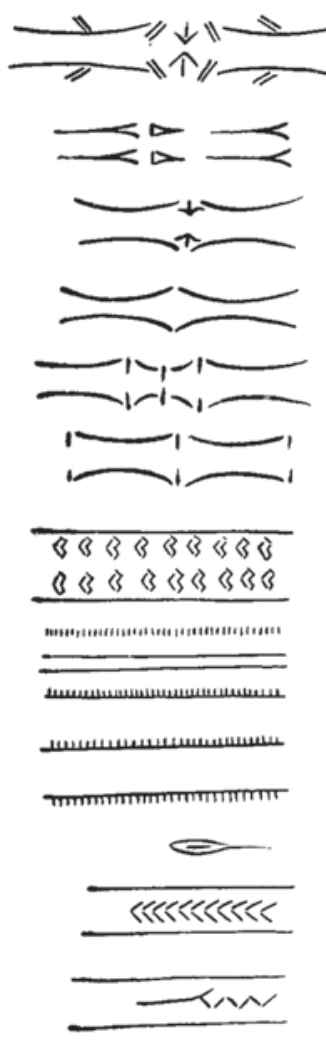

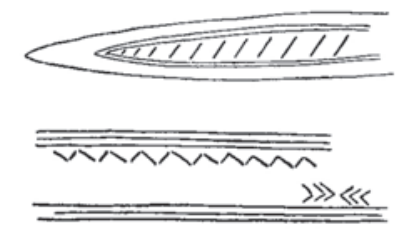
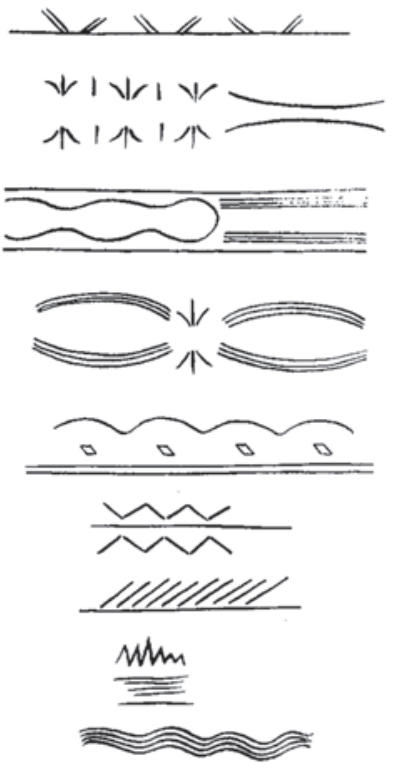

Fig. 34. Cuadro sintético de temas complejos longitudinales simétricos (en sentido apaisado) sobre varillas de Isturitz/col. Passemard (según E. Passemard 1944). I Synthetic table of complex longitudinal symmetrical themes (in landscape direction) on Isturitz / col. Passemard rods (according to E. Passemard 1944).
En depósitos del Magdaleniense medio del norte de la Península Ibérica, se han recuperado estas decoraciones en sendas varillas de los niveles $\mathrm{C}$ del Cueto de la Mina, B de La Paloma (Barandiarán, 1972: láms. 24.10 y 24.24) y D de Abauntz (Utrilla y Mazo, 1996: fig. 10.11), en tres de Las Caldas (Corchón, 1990: fig. 2dcha; y $n^{\circ}$ 07422 del Museo de Arqueología de Oviedo), etc.

\subsubsection{Haces de líneas curvadas combinadas con áreas reservadas}

Este tipo de trazados es "mucho menos frecuente en los yacimientos contemporáneos y están dotados de una técnica algo diferente: grupos de largas líneas ondulosas, constituidas por relieves y ranuras, tan finos los unos como las otras, curvadas en arco sobre la varilla" (Saint-Périer, 1936: 84).

Pueden recordarse los pocos testimonios de este grafismo publicados hasta ahora7 (figura 35).

Dos fragmentos de "instrumentos de asta de reno... adornados con líneas curvas concéntricas" recuperados por L. Nelli en Espélugues/Lourdes y publicados por Piette (1907: láms. XXI.3 y XXXVI). M. Chollot (1980: 210), con su habitual recurso a la deconstrucción de las decoraciones del arte mobiliar, los ha descrito como "filas de arcos (arceaux) embutidos... de ramas muy desiguales" (pieza 55340A -Musée d'Archéologie Nationale de Saint-Germain-en-Laye-) y "de laterales incompletos" (pieza 55340B).

En las excavaciones de 1909-1910 (J. Bouyssonie) en Hornos de la Peña se obtuvo el fragmento medial de una varilla de sección subrectangular grabada con "un haz de estrías curvas" (Feruglio, 1998: 192).

E. Passemard (1922: 35-37 y figs. 32-33) al excavar en la Gran Sala de Isturitz el "bello y destacadamente rico estrato E" encontró "dos pequeños bastoncillos de asta de reno... con dibujos que son muy probablemente de vegetales... los mismos motivos en uno y otro aunque no haya entre ellos una identidad absoluta". Existen referencias posteriores a esas varillas y sus grabados: Breuil y Saint-Périer (1927: 76 y fig. 29.8) incluyen la decoración en "trazos ondulados" entre las "esquematizaciones de peces", Passemard (1944: 56 y lám. XXXV.2) alude a sus "decoraciones

\footnotetext{
7 El argumento gráfico es omitido por Feruglio (1998: 191-192) al resumir los tipos de decoraciones sobre varillas semicilíndricas del Pirineo francés. ${ }^{8}$ En su ficha con dibujo y fotografía se recoge (Barandiarán, 1972: 134-135) la alusión de los descubridores a su depósito en el nivel d, del Magdaleniense "antiguo", recordando su proximidad formal a ejemplares del Magdaleniense medio de Isturitz.
} 

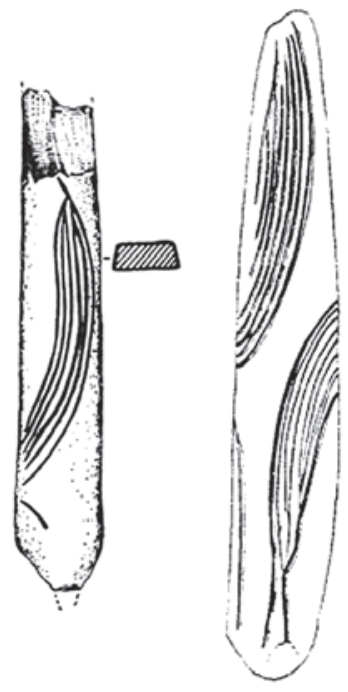

b

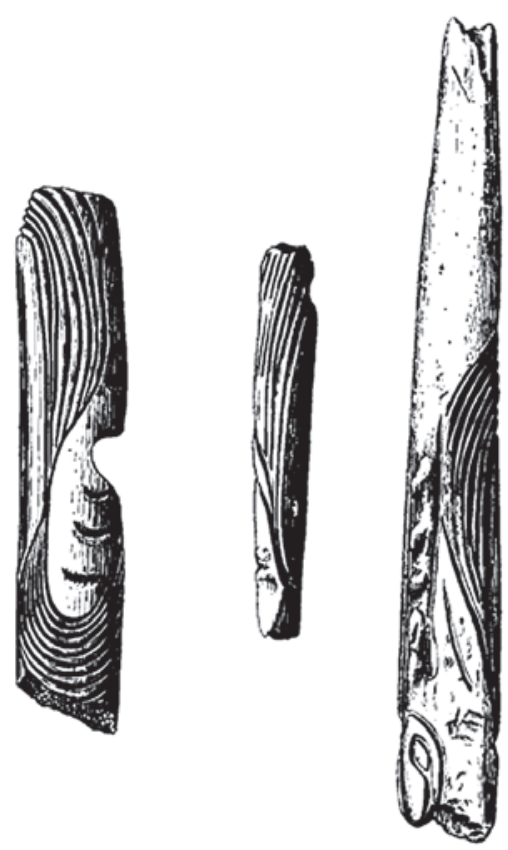

d

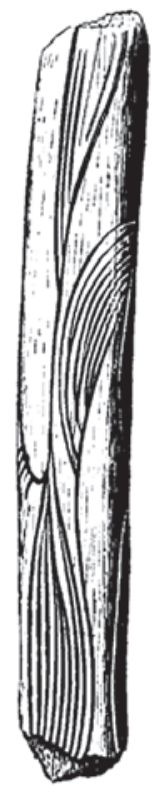

f

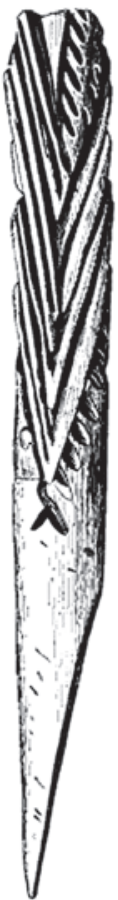

g

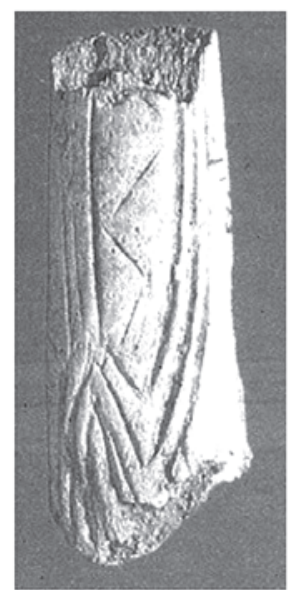

h

Fig. 35. Grabados de haces de líneas, como los de la varilla 3 de Ezkuzta, sobre fragmentos (de izquierda a derecha) de Hornos de la Peña, Isturitz/col. Passemard, Isturitz/col. Saint-Périer (cinco ejemplares) y La Viña (muy ampliado) (tomados de I. Barandiarán 1972. E. Passemard 1922. R. de Saint-Périer 1936 y J. Fortea 1992). / Engravings of line bundles, such as those of rod 3 of Ezkuzta, on fragments (from left to right) of Hornos de la Peña, Isturitz / col. Passemard, Isturitz / col. Saint-Périer (five copies) and La Viña (widely spread) (taken from I. Barandiarán 1972, E. Passemard 1922, R. de Saint-Périer 1936 and J. Fortea 1992).

vegetales y ondas" y Sauvet et al. (2008: fig.9.2) deciden que esas "líneas paralelas sinuosas... estrechamente yuxtapuestas" son tema propio del Magdaleniense medio.

La excavación del nivel II (Magdaleniense medio) de la misma Gran Sala de Isturitz por Saint-Périer aportó cinco fragmentos de varillas decoradas en dos modalidades (Saint-Périer, 1936: 84-86 y figs. 50 y 49.7): cuatro grabadas con "grupos de largas líneas onduladas constituidas por relieves y ranuras, tan finos los unos como las otras, curvadas en arco sobre la varilla"9 y una que presenta "adornos compuestos" constituidos por series de ángulos embutidos unos en otros.

J. Fortea recogió en el estrato IV del sector central (atribuido al Magdaleniense medio) del abrigo de La Viña un corto fragmento medial de "varilla plano-convexa vigorosamente decorada". Según su fotografía (Fortea, 1992: 20 y fig. 3) parecen parte de haces de surcos curvados convergentes.

En suma, en la docena de ejemplares hoy conocidos con este argumento gráfico destacan con mucho (son el $75 \%$ ) las procedentes del espacio pirenaico (siete de Isturitz y dos de Lourdes) sobre las presentes más al oeste (sendas de Hornos de la Peña y La Viña, más la $n^{\circ} 3$ de Ezkuzta.

\subsection{Adscripción cronocultural de las varillas de Ezkuzta}

Las tres varillas fueron recuperadas en el mismo cuadro L22: los doce trozos de la varilla 1 en la capa 32 (del sector 5), la completa 2, en la capa 23 y la completa 3, desplazada en dos lotes al derrumbarse el testigo allí situado (el fragmento en posición primaria corresponde a la capa 5).

La datación numérica del conjunto ha resultado muy difícil, debido al intenso lavado de la secuencia que ha inhabilitado las muestras sobre hueso para su datación (EZK- 1 y EZK-3). A medida que la excavación ha progresado, hemos podido disponer de otros materiales para su datación, como carbón de las estructuras de hogar (EZK-2, EZK-4 y EZK-5) y un fragmento de molar de Equus sp. (EZK-6). Los resultados obtenidos en los laboratorios BETA, de Miami (EEUU) y ORAU, Oxford (Reino Unido) son los siguientes:

\footnotetext{
${ }^{9}$ Proponiendo que "el modelo natural que ha podido inspirarlas parece más vegetal que animal; las largas hojas estrechas de algunas plantas acuáticas sumergidas adquieren esa apariencia cuando la corriente las hace ondular".
} 


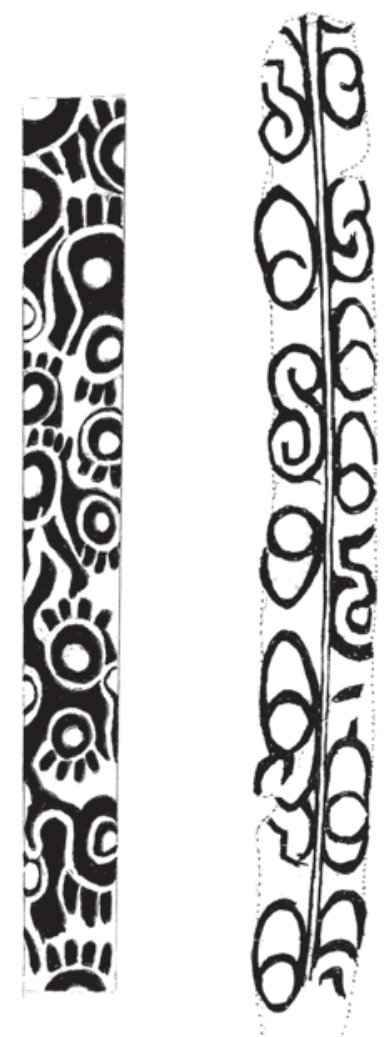

Fig. 36. Síntesis de los argumentos gráficos de las tres varillas de Ezkuzta: los curvilíneos (con surcos profundos y anchos) en la tentativa sobre los tres trozos discontinuos de la 1 (a la izquierda), en la completa 2 (en el centro) y los trazos agrupados en haces en torno a zonas reservadas de la completa 3 (a la derecha). / Synthesis of the graphic arguments of the three Ezkuzta rods: the curvilinear (with deep and wide grooves) in the attempt on the three discontinuous pieces of the 1 (on the left), in the complete 2 (in the center) and the traces grouped in bundles around reserved areas of complete 3 (on the right).

- EZK-4 (carbón): Beta-426856; 11240 × 50 BP. Entre 13145-13060 cal. BP

- EZK-2 (carbón): Beta-386707; 14160 土 50 BP. Entre 17400-17085 cal BP.

- EZK-5 (carbón): Beta-426857; 13580 × 50 BP. Entre 16495-16230 cal BP.

- EZK-6 (diente): OxA-39002; $14422 \pm 51$ BP. Entre 17803-17386 cal BP.

Aunque se podría entender que hay cierta inversión en las fechas EZK-2 y EZK-5, es preciso matizar que EZK-5 se corresponde con pequeños fragmentos de carbón obtenidos de modo algo más difuso sobre los cuadros L22 y L24 y en un contexto con buzamientos tan pronunciados como los de Ezkuzta, es posible que esta muestra haya incorporado alguna brizna más reciente que haya desvirtuado algo la media. En este sentido, parece verosímil un intervalo para estas piezas entre el 14160 y el $14422 \mathrm{BP}$, y sobre cronologías calibradas, entre el 17085 y 17803 cal BP

El argumento gráfico desarrollado sobre las varillas 1 y 2 es conforme con el de las varillas (que suman hoy entre sesenta y tres y sesenta y cinco ejemplares) con temas curvilíneos grabados profundamente o en relieve. Desde la percepción de sus manifestaciones por E. Piette y al aportarse sus efectivos decisivos por E. Passemard y R. de Saint-Périer ${ }^{10}$ es ahora aceptado ese argumento unánimemente (p.e. en la opinión de A. Leroi-Gourhan) ${ }^{11}$ como "propio de" el Magdaleniense medio pirenaico.

La varilla 3 se integra en la escasa docena de ejemplares decorados con haces de líneas curvadas grabadas que se combinan con áreas reservadas: también se adscriben al Magdaleniense medio. Faltan confirmar las dos piezas de Lourdes (de referencia estratigráfica no controlada) y la de Hornos de la Peña, pieza recuperada en un nivel magdaleniense que se consideró genéricamente "antiguo" y al que se han hecho matizaciones hacia lo "medio" en los dos catálogos mayores del arte mueble paleolítico cantábrico (Barandiarán, 1972: 134-135, Corchón, 1986: 301-302).

G. Sauvet et al. (2008: 51-52 y fig.9) han valorado siete de estas piezas (una de Hornos de la Peña, cuatro de Isturitz y dos de Lourdes) con "decoración ondulante constituida por surcos paralelos estrechamente yuxtapuestos" (o de "lineas paralelas sinuosas") como "elementos artísticos del período 14500-13300 BP (en el Magdaleniense medio)... ejemplos que confirman la unificación cultural cántabro-aquitana-pirenaica".

\section{DISCUSIÓN}

1. En cuanto a UBICACIÓN EN EL YACIMIENTO, las tres varillas se encontraron en sectores contiguos y profundidades (relativas) próximas del mismo cuadro L22.

2. En cuanto a ENTIDAD DEL SOPORTE las piezas de Ezkuzta son, como prácticamente todas las varillas magdalenienses del Sudoeste europeo, de asta de Cérvido; más en concreto, no cuesta referirlas espe-

\footnotetext{
${ }^{10}$ Así, el pensamiento recurrente de Saint-Périer al presentar las "admirables piezas esculpidas" de Lespugue que "indican las difusión por los Pirineos de este arte original, conocido inicialmente en Lourdes y en Arudy y que ahora se llega a encontrar hasta en el Lot" (Saint-Périer, 1920: 234) o las dos varillas de la Sala Saint-Martin de Isturitz pertenecientes al "grupo muy homogéneo y hasta ahora exclusivamente pirenaico de las varillas esculpidas Ilamadas 'con espirales' (Saint-Périer, 1930: 102-104).

${ }^{11}$ Entre las varillas semicilíndricas del arte paleolítico occidental se individualiza (Leroi-Gourhan et al., 1995: 78) "un grupo limitado al Oeste pirenaico con Lespugue, Arudy, Lourdes y sobre todo Isturitz, presentando objetos bastante diferentes pero caracterizados todos por su decoración complicada... objetos tan sorprendentes como los con grecas y losanges sobre marfil de Mezine...".
} 


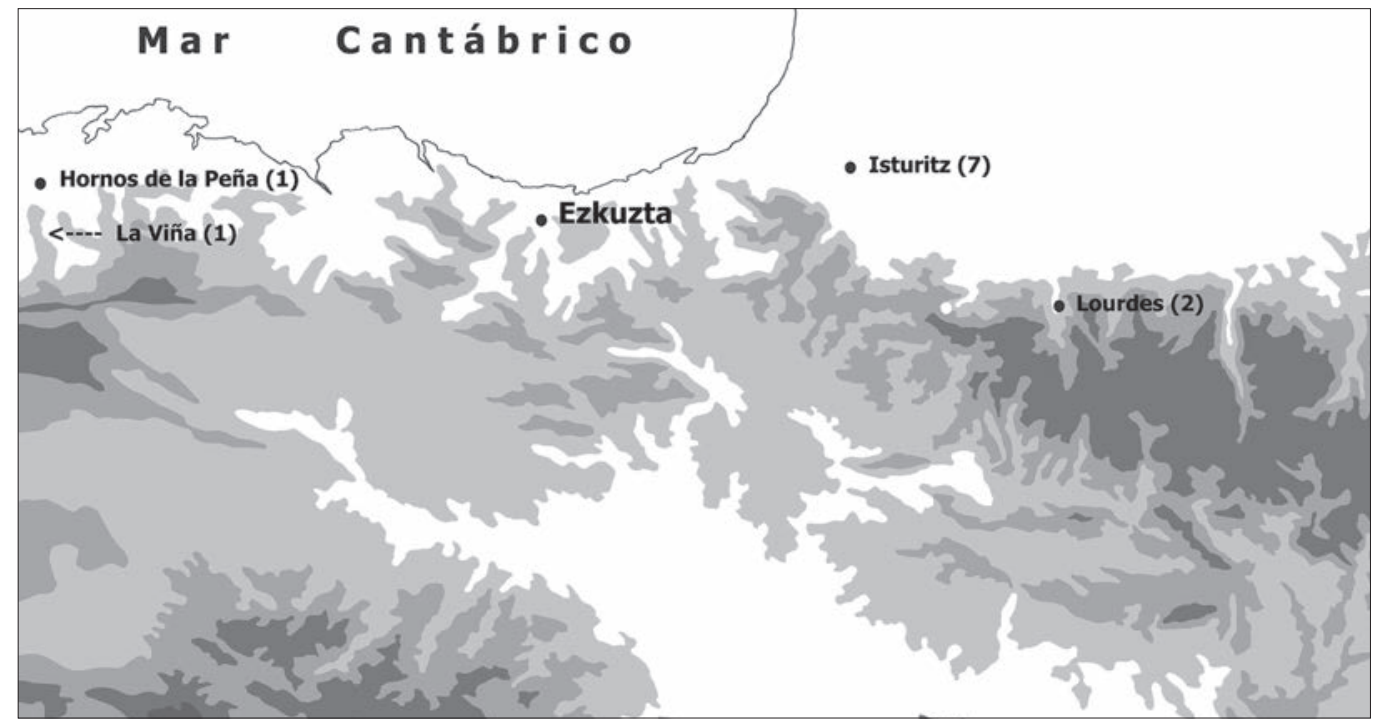

Fig. 37. Cuadro de dispersión de las varillas con decoración de haces de líneas, como la del ejemplar 3 de Ezkuzta. / Scattering table of the rods with decoration of beams of lines, such as that of rod 3 of Ezkuzta. cíficamente al reno como la totalidad de las similares norpirenaicas ${ }^{12}$.

3. En cuanto a ESTADO DE CONSERVACIÓN siendo normal la fragmentación de buena parte de las manufacturas paleolíticas de formato alargado sobre soportes orgánicos (agujas, punzones, costillas o tubos decorados, etc. en hueso y azagayas, arpones, bastones perforados o propulsores, etc. en asta) resulta abrumadoramente dominante en piezas tan largas y delgadas como las varillas. Hace un siglo, esta circunstancia ya fue advertida por E. Passemard (1916: 302-303) y ha sido contrastada por V. Feruglio sobre una muestra de ocho centenares de varillas (decoradas o no, del Magdaleniense medio de Enlène e Isturitz) donde son ínfima minoría las completas (algo menos del 4\%, pues sólo están 30 enteras frente a 768 fragmentos).

De las 75 referencias a varillas repasadas, la mitad $(50,7 \%)$ corresponde a fragmentos menores (longitud $<70 \mathrm{~mm}$.), una tercera parte (33,3\%) a medianos y sólo un $12 \%$ a los grandes. Sólo están prácticamente completas la 2 de Ezkuzta y la pieza de Poggenwisch entre las sesenta y tres dotadas de curvilíneos en relieve y la $\mathrm{n}^{\circ} 3$ de Ezkuzta entre las doce con líneas curvadas en haces.

4. Conocemos con seguridad TAMAÑO Y FORMA de las tres varillas prácticamente completas (dos de Ezkuzta y la de Poggenwisch) y podemos tentar la restitución de otras ocho ${ }^{13}$ recuperadas en fragmentos muy o bastante grandes: medirían en $\mathrm{mm}$. de longitud $\mathrm{x}$ anchura los $275 \times 14,4,260 \times 14,5$ y $270 \times 18,5$ (tres ejem- plares de Isturitz), 160x15 y 220x9,4 (dos de Lourdes), 180x15,3 y 160x16 (dos de Lespugue), 170x16 (una de Arudy), apenas 150x10 ('el bastón' de Poggenwisch), 250x12,9 (varilla 2 de Ezkuzta) y 200×14,3 (varilla 3 de Ezkuzta) ${ }^{14}$. Todas ellas tienen forma larga y estrecha, con variantes entre 150 y $275 \mathrm{~mm}$. de longitud y entre 10 y 18,5 de anchura.

Son más las SECCIONES TRANSVERSAS aplanadas (sean planoconvexas, semicilíndricas o subrectangulares) como Ezkuzta 1 y 3 que las macizas (subcirculares, subcuadrangulares o circulares) como Ezkuzta 2. En el cuadro general de varillas usado (recordando que las referencias escritas y gráficas anteriores a mediado el siglo pasado no precisan medidas de espesor y pocas veces incluyen dibujo de las secciones) las varillas de sección aplanada presentan una media de anchura de 14,3 mm: con esa media coincide precisamente la anchura de la 3 de Ezkuzta. Por su parte Ezkuzta 1 se incluye, con sus 18,9 mm, entre todas las más anchas de aquel cuadro general: cinco de Isturitz (anchuras de $21,3,19,5,18,8,18,5$ y 18,3), una de Bourrouilla $(18,8)$ y una de Lourdes $(18,3)$.

Todas las PUNTAS de la reducida muestra de varillas que las conservan están o aguzadas o relativamente redondeadas (como sucede en las $n^{\circ} 2$ y 3 de Ezkuzta). En el también corto efectivo de BASES conservadas es frecuente el recurso al redondeado o a un ligero apuntamiento y excepcional su acondicionamiento biselado: sea bisel plano (sobre la cara superior de una varilla de Lespugue y sobre la cara inferior de Ezkuzta

\footnotetext{
${ }^{12}$ Se puede discutir alguna identificación disonante a favor del marfil (dos ejemplares de Lourdes: Piette, 1907: láms. XIV.6 y XIV.7) o del hueso (dos de Arudy: Chollot, 1964: 215).

${ }^{13}$ Dibujo y descripción de esas piezas en Saint-Périer (1929: figs. 3.1, 4 abajo y derecha, 6.1 y 6.2), Saint-Périer (1936: figs. 51.6, 51.7 y 51.9) y Bosinski (1978)

${ }^{14} Y$, en tentativa discutible de reconstitución, entre los 245 y (a lo más) 280 mm de longitud y no más de 20 mm. de anchura, de Ezkuzta 1.
} 
2) u oblicuo sobre los laterales de la base (un solo bisel estriado en una varilla de Lespugue (Saint-Périer, 1929: fig. 1, 1936: 90-91) y probablemente sendos biseles a uno y otro lados de Ezkuzta 3).

5. Los ARGUMENTOS GRÁFICOS de las tres varillas de Ezkuzta se sirven de temas, trazado y disposición distintos (figura 36). Las varillas 1 y 2 acogen unidades gráficas cortas curvilíneas y de surco muy profundo y ancho (que produce las molduras en fuerte relieve que se reservan derivada o intencionadamente entre los surcos). La varilla 3 presenta unidades gráficas alargadas en haces de surco mucho más estrecho y fino.

Frente al desarrollo a campo completo único de la varilla 1 que acoge una yuxtaposición ininterrumpida de unidades gráficas de arriba abajo y de derecha a izquierda, en las 2 y 3 se trazó un marcador longitudinal que organiza la disposición de las unidades gráficas a los lados: explícito como moldura en relieve que genera los campos laterales en la 2 y grabado muy fino (como línea "de esbozo") en la 3. A este respecto y a partir del cuadro general de contingencia de varillas que manejamos, se comprueba que, frente a la mayoría de las sesenta y cuatro varillas dotadas de grafismos curvados (surcos profundos y/o en relieve) que están cubiertas, como la varilla 1 de Ezkuzta, a campo total por una enrevesada combinación de unidades gráficas, sólo ocho (cinco de Isturitz, tres de Arudy - Piette, 1907: láms. LXXXV.3, 4 y 6, Saint-Périer, 1930: fig. 86, 1936: figs. $53.4,7,11$ y 14-) se sirven de la moldura central a lo largo para distribuir en dos campos longitudinales paralelos un contenido gráfico similar como en Ezkuzta 2.

De acuerdo con la opinión general de R. de Saint-Périer (1929: 53-60 y figs. 8 y 10-12 con un prolijo desglose) hay que aceptar que la aparente gran diversidad de grafemas curvilíneos, espiraliformes o sinuosos sobre varillas ( 1 y 2 de Ezkuzta y todas las de la muestra que revisada) se aúna de hecho en pocos argumentos gráficos: "ofrecen un pequeño número de temas diferentes, dispuestos con simetría, sin norma aparente" (Saint-Périer, 1929: 60).

Los trozos recuperados de Ezkuzta 1 retienen partes de, probablemente, hasta once unidades gráficas donde se combinan una forma circular (con apéndice serpentiforme) y otras en dientes (o "sierra"), al modo que en varillas de Lespugue (Saint-Périer, 1929: figs. 1 y 2).

Las doce unidades gráficas de Ezkuzta 2 son cerradas (= vueltas sobre sí) y alargadas: unas tienen forma ovalada (óvalo cerrado, al modo de los signos en almendra de la propuesta de Saint-Périer) que acoge un círculo en su interior, como las grabadas sobre varillas de Lespugue (Saint-Périer, 1929: figs. 7.2 y 11.64), otras son serpentiformes o en 'S' como las 'espirales' presentes en ejemplares de Arudy, Lourdes y Lespugue (op. cit. figs. 8. 24-29). En la varilla de Ezkuzta esas formas gráficas se trazan tanto sueltas (sólo óvalos son I1, I3, I5, D1, D2, D4 y D6 y sólo serpentiformes son 14, 16 y D5) como combinadas (óvalo+serpentiforme en 12 y D3).
Ante el temario curvilíneo abigarrado que cubre todo el dorso de las varillas 1 y 2 dudamos de calificarlo técnicamente como "grabados o... esculpidos en relieve" (Saint-Périer, 1939: 263). Pues en el aspecto final ("la visión" o "lectura") del argumento espiraliforme y/o sinuoso de las dos varillas se aunan dos elementos gráficos: es "efectivo" el conjunto de grabados profundos ejecutados, en tanto que son "inducidos" o derivados los relieves o molduras reservados (con probabilidad intencionadamente) entre aquellos anchos y profundos surcos.

La composición decorativa de Ezkuzta 3 dispone a campo total haces de incisiones profundas en torno a zonas reservadas. Este argumento gráfico es escaso en el Tardiglaciar sureuropeo, con sólo una docena de ejemplos: dos en Lourdes (colección Nelli), siete en Isturitz (dos en excavaciones de Passemard y cinco en excavaciones de Saint-Périer) y sendas en Hornos de la Peña, La Viña y Ezkuzta. El argumento de Ezkuzta 3 es el de mayor complejidad gráfica de todo este elenco, pues siendo lo común que las líneas incisas sean sólo curvilíneas o sólo rectilíneas (salvo, acaso, en el fragmento de la Viña) y que la articulación (o contacto) entre los haces formados por esas líneas sean en ángulo recto (caso de Isturitz) o curvo (Lourdes), en la varilla de Ezkuzta se presentan trazos curvilíneos y rectilíneos combinados tanto en haces como en angulaciones.

6. Se puede asegurar la ADSCRIPCIÓN CRONOCULTURAL de los tres ejemplares de Ezkuzta con una aproximación de cronología absoluta en el propio yacimiento y el consenso de referencia cultural del efectivo de las varillas semejantes a ellos.

Como se ha indicado anteriormente, consideramos más probable un intervalo para estas piezas entre el 14160 y el 14422 BP, y sobre cronologías calibradas, entre el 17085 y el 17803 cal BP. Sin embargo, contamos también con sendas fechas más recientes, suficientemente comentadas, respectivamente de $13580 \pm$ 50 BP (16495-16230 cal BP) y $11240 \pm 50$ BP (1314513060 cal BP). En todo caso, la primera de estas fechas algo más recientes entra dentro del marco cronocultural del Magdaleniense medio, al que se atribuyen las varillas decoradas de esta variedad.

7. La Arqueología reconoce como MARCADOR CULTURAL del "Magdaleniense medio pirenaico" el argumentario gráfico (las unidades abigarradas en sistemático horror vacui) del lote de varillas similares a las de Ezkuzta: todas concentradas en el espacio (tercios occidental y central del territorio norpirenaico) y el tiempo. Este peculiar sistema "decorativo" (no muy abundante, de cierto) caracteriza (junto a más generalizados rasgos de equipamiento y demografía sensu lato) el gran espacio cántabro-pirenaico en el Magdaleniense medio (IV), como ekúmene con un lenguaje gráfico (koiné) común (Corchón, 2005, Barandiarán, 2015) (figuras 33 y 37 ).

8. Sea cual sea su fórmula gráfica, la Arqueología no ha podido decidir LA INSPIRACIÓN Y EL DESTINO de varillas tan prolijamente decoradas. Ante las prime- 
ras de Isturitz y las ya conocidas en otros sitios pirenaicos, intentó explicar E. Passemard (1920: 153) sus diferencias "menores": dan "la impresión de una indecisión en el conjunto, de que el artista carecía de un plan preestablecido, que se dejaba llevar por la inspiración o que era guiado por los azares de la forma y por la preocupación de cubrir toda la superficie a decorar debiendo recurrir para ello a elementos determinados, conocidos y aprendidos, producto de otras formas, de deformaciones, o de simplificaciones, que pueden seguir conservando su sentido". Saint-Périer (1939: 266-269) sugirió, por su parte, algunas razones que aclararían el uso de esas manufacturas: la misma forma de los iconos (¿"esquematizaciones de"?), los paralelos etnográficos de forma+decoración (en lo ritual/ceremonial,...), los motivos de su casi absoluto estado de fragmentación... Ninguna de ellas convence.

9. En fin, IMPORTAN MUCHO LAS TRES VARILLAS DE EZKUZTA en el contexto de las artesanías gráficas del Magdaleniense medio del sudoeste de Europa por dos razones: i, la inmejorable conservación de dos de ellas; y ii, su aportación numérica al escaso repertorio de las hasta ahora conocidas, que es tan magro (algo más de sesenta) en el caso de las que soportan espiraliformes en grabado profundo o en relieve (como Ezkuzta 1 y 2) y absolutamente testimonial (apenas una docena) en el de las que portan haces de líneas (como Ezkuzta 3).

\section{AGRADECIMIENTOS}

Este trabajo ha sido parcialmente financiado por el Departamento de Cultura de la Diputación Foral de Gipuzkoa, los Grupos Consolidados de Investigación en Prehistoria IT-622-13 e IT-1223-19 y los proyectos de investigación del Plan Nacional PALEOGATE (HAR201453536-52P) y PATHFINDER (HAR2017-82483-C3-1-P). Antxieta Arkeologia Taldea ha contribuido en los trabajos de campo y de adecuación y mantenimiento de la cueva. Una de las dataciones incluidas en este artículo ha sido realizada en el laboratorio de radiocarbono de la Universidad de Oxford (ORAU). Agradecemos a los revisores de este artículo su contribución para mejorarlo.

\section{BIBLIOGRAFÍA}

Altuna, J., Armendáriz, A., Etxeberria. F., Mariezkurrena, K., Peñalver, X., J. Zumalabe, F.J., 1995. Carta arqueológica de Gipuzkoa II. Cuevas. Munibe Suplemento 10. San Sebastián.

Arambourou, R., Delpech, F., Evin, J., Laurent, P., Paquereau, M.M., Schvoerer, M., Thibault, C., 1978. Le gisement préhistorique de Duruthy à Sorde-l'Abbaye (Landes). Bilan des recherches de 1958 à 1975. Mémoires de la Société Préhistorique Française 13.

Barandiarán, I., 1967. El Paleomesolítico del Pirineo Occidental. Bases para una sistematización tipológica del instrumental óseo paleolítico. Monografías Arqueológicas 3, Universidad de Zaragoza.
Barandiarán, I., 1972. Arte mueble del Paleolítico cantábrico. Monografías Arqueológicas 14, Universidad de Zaragoza.

Barandiarán, I., 2006. Imágenes y adornos en el arte portátil magdaleniense. Editorial Ariel Prehistoria, Barcelona.

Barandiarán, I., 2015. Contextualización arqueológica de La Covaciella. Una coiné pirenaico-cantábrica en el Magdaleniense medio. In: García-Diez, M., Ochoa, B., Rodríguez-Asensio, J.A. (Eds.), Arte rupestre paleolítico en la cueva de La Covaciella (Inguanzo, Asturias), 125-144. Gobierno del Principado de Asturias, Oviedo.

Bosinski, G., 1978. Der Poggenwischstab. Bonner Jahrbücher 178, 83-92.

Bosinski, G.,1982. Die kunst der Eiszeit in Deutschland und in der Schweiz. Habelt, R., Kathaloge vorund frühgeschichtlicher Altertümer 20. GMBH, Bonn.

Bosinski, G., 1990. Homo sapiens. L'histoire des chasseurs du Paléolithique supérieur en Europe (40000-10000 av JC.). Érrance, Paris.

Breuil, H., Lantier, R., 1959. Les Hommes de la Pierre ancienne (Paléolithique et Mésolithique), nouv. Édition Payot, Paris.

Breuil, H., Obermaier, H., 1912. Les premiers travaux de l'Institut de Paléontologie Humaine. Extrait de L'Anthropologie XXIII(1), 1- 27, Masson et Cie, Paris.

Breuil, H., Saint-Périer, R. de, 1927. Les poissons, les batraciens et les reptiles dans l'art quaternaire. Archives de l'Institut de Paléontologie Humaine, mémoire 2, Masson, Paris.

Capitan, L., Peyrony, D., 1928. La Madeleine. Son gisement, son industrie, ses oeuvres d'art. Publications de l'Institut International d'Anthropologie $\mathrm{n}^{\circ} 2$, Émile Nourry, Paris.

Cheynier, A., 1965. Comment vivait l'Homme des Cavernes à l'Age du Renne. Éditions du Scorpion, Paris.

Chollot, M., 1964. Musée des Antiquités Nationales. Collection Piette. Art mobilier préhistorique. Éditions des Musées Nationaux, Paris.

Chollot, M., 1980. Les origines du graphisme symbolique. Essai d'analyse des écritures primitives en Préhistoire. Fondation Singer-Polignac, Paris.

Corchón, S., 1986. El arte mueble paleolítico cantábrico: contexto y análisis interno. Centro de Investigación y Museo de Altamira monografías 16. Ministerio de Cultura, Madrid.

Corchón, S., 1990. La Cueva de Las Caldas (Priorio, Oviedo). Investigaciones efectuadas entre 1980 y 1986. Excavaciones Arqueológicas en Asturias 1983-86, 37-53.

Corchón, S., 2005. Europa 16500-14000 a. C.: un lenguaje común. In: Arias, P., Ontañón, R. (Eds.), La materia del lenguaje prehistórico. El arte mueble paleolítico de Cantabria en su contexto Ontañón, 105-126, Ministerio de Cultura, Instituto Internacional de Investigaciones Prehistóricas de Cantabria y Gobierno de Cantabria Santander.

Coutil, L., 1916. L'ornamentation Spiraliforme. Périodes Paléolithique et Néolithique Ages du Bronze et du Fer. Bulletin de la Société Préhistorique Française 13(7), 385-484.

Feruglio, V., 1992. Fiche baguettes demi-rondes. In: Camps-Fabrer, M (ed), Fiches typologiques de l'industrie osseuse préhistorique. Cahier V. Bâtons percés, baguettes, 7183. C.E.D.A.R.C., Treignes.

Feruglio, V., 1998. Les baguettes demi-rondes de l'Espagne cantabrique et leur comparaison avec les Pyrénées françai- 
ses. In: Sauvet, G. (Coord.), Art et Société dans le Magdalénien Pyrénéen. Projet collectif de Recherche. Rapport triennal 1996-199), 187-196, Toulouse.

Fortea, J., 1992. Abrigo de La Viña. Informe de las campañas 1987 a 1990. Excavaciones arqueológicas en Asturias 198790, 19-28.

Fritz, C., Roussot, A., 1999. L'art mobilier. In: Chauchat, C. (Ed.), L'habitat magdalénien de la Grotte de Bourrouilla à Arancou (Pyrénées Atlantiques), Gallia Préhistoire 41, 54-97.

Graziosi, P., 1960. Palaeolithic art. Faber \& Faber, London.

Iriarte-Chiapusso, M.J., Antxieta Jakintza Taldea, 2013. Cueva de Ezkuzta (Azpeitia). I Campaña. Arkeoikuska 2012, 261-262. Gobierno Vasco, Vitoria-Gasteiz.

Iriarte-Chiapusso, M.J., Antxieta Jakintza Taldea, 2014. Cueva de Ezkuzta (Azpeitia). II Campaña. Arkeoikuska 2013, 281282. Gobierno Vasco, Vitoria-Gasteiz.

Iriarte-Chiapusso, M.J., Antxieta Jakintza Taldea, 2015. Cueva de Ezkuzta (Azpeitia). III Campaña. Arkeoikuska 2014, 305. Gobierno Vasco, Vitoria-Gasteiz.

Iriarte-Chiapusso, M.J., Antxieta Jakintza Taldea, 2016. Cueva de Ezkuzta (Azpeitia). IV Campaña. Arkeoikuska 2015, 301302. Gobierno Vasco, Vitoria-Gasteiz.

Iriarte-Chiapusso, M.J., Antxieta Jakintza Taldea, 2017. Cueva de Ezkuzta (Azpeitia). V Campaña. Arkeoikuska 2016, 340.-, Gobierno Vasco, Vitoria-Gasteiz.

Iriarte-Chiapusso, M.J., Antxieta Jakintza Taldea, 2018. Cueva de Ezkuzta (Azpeitia). VI Campaña. Arkeoikuska 2017, 353354. Gobierno Vasco, Vitoria-Gasteiz

Leroi-Gourhan, A., 1965, Préhistoire de l'Art Occidental. Éditions d'Art Lucien Mazenod, Paris.

Leroi-Gourhan, A., Delluc, G., Delluc, B., 1995. Préhistoire de l'art occidental. Citadelle \& Mazenod, Paris.

Mons, L., 1981. Les baguettes demi-rondes du Paléolithique supérieur occidental: analyse et réflexions. Antiquités Nationales 12/13, 7-19.

Passemard, E., 1916. Sur les Baguettes demi-rondes. Bulletin de la Société Préhistorique Française 13, 301-307.

Passemard, E., 1920. Les Spirales de la caverne d'Isturitz. Bulletin de la Société Préhistorique Française 17, 150-154.

Passemard, E., 1922. La Caverne d'Isturitz. Revue Archeologique 15, 1-45.

Passemard, E., 1944. La Caverne d'Isturitz en Pays Basque. Préhistoire IX. Presses Universitaires de France, Paris.

Piette, E., 1894. Notes pour servir à l'histoire de l'art primitif. L'Anthropologie 5(2), 129-146.

Piette, E., 1904. Études d'Ethnographie Préhistorique. VII. Classification des sédiments formés dans les cavernes pendant l'âge du Renne. Premier article. L'Anthropologie 15, 129-176.

Piette, E., 1907. L'Art pendant l'Âge du Renne. Album de cents planches dessinées par J. Pilloy. Masson, Paris.

Saint-Périer, R. de, 1920. La Grotte des Harpons à Lespugne (Haute-Garonne). L'Anthropologie 30, 209-234.

Saint-Périer, R. de, 1929. Les baguettes sculptées dans l'art paléolithique. L'Anthropologie 39, 43-64.
Saint-Périer, R. de, 1930. La grotte d'Isturitz. I. Le Magdalénien de la Salle de Saint-Marcel. Archives de l'Institut de Paléontologie Humaine mémoire 7. Masson, Paris.

Saint-Périer, R. de, 1936. La grotte d'Isturitz. II. Le Magdalénien de la Grande Salle. Archives de l'Institut de Paléontologie Humaine mémoire 17. Masson, Paris.

Saint-Périer, R. de, 1939. Nouvelles baguettes sculptées des Pyrénées. Mélanges de Préhistoire et d'Anthropologie offerts par ses collègues, amis et disciples au Professeur Comte $\mathrm{H}$. Begouën, 263-269, Éditions du Museum, Toulouse.

Saint-Périer, R. de, Saint-Périer, S., 1959. Le Couserans fait partie du Centre d'Art Pyrénéen des Baguettes Sculptées. Bulletin de la Société Préhistorique de l'Ariège 14, 10-15.

Sauvet, G., Fortea, J., Fritz, C., Tosello, G., 2008. Crónica de los intercambios entre los grupos humanos paleolíticos. La contribución del arte para el periodo 20000-12000 años BP. Zephyrus 61, 33-59.

Utrilla, P., Mazo, C., 1996. Le Paléolithique supérieur dans le versant sud des Pyrénées. Communications et influences avec le monde pyrénéen français. In: Pyrénées Préhistoriques. Arts et Société. Actes du 118 è congrès nacional des societés historiques et scientifiques, 243-262. C.T.H.S., Paris.

Zervos, C., 1959. L'art de l'époque du renne en France. Cahiers d'Art, Paris. 